Centro de Estudios Constitucionales de Chile Universidad de Talca

"Las deficiencias de la fórmula 'derecho a vivir en un medio ambiente

libre de contaminación’ en la Constitución chilena y algunas propuestas para su revisión”

Gonzalo Aguilar Cavallo

\title{
LAS DEFICIENCIAS DE LA FÓRMULA \\ "DERECHO A VIVIR EN UN MEDIO AMBIENTE LIBRE DE CONTAMINACIÓN" EN LA CONSTITUCIÓN CHILENA Y ALGUNAS PROPUESTAS PARA SU REVISIÓN*
}

\author{
The Shortcomings of the Formulation \\ of the Right to a Healthy Environment in Chilean \\ Constitution and Some Proposals for its Revision
}

\author{
Gonzalo Aguilar Cavallo** \\ Universidad de Talca \\ gaguilar@utalca.cl
}

RESUMEN: Este trabajo pretende examinar las deficiencias que presenta la actual formulación del derecho a vivir en un medio ambiente libre de contaminación en la Constitución chilena y, a partir de este análisis, efectuar una propuesta que abarcaría la denominación del derecho, su contenido y su delimitación. Este último examen se haría a la luz de la doctrina, la jurisprudencia y el derecho internacional de los derechos humanos. El trabajo concluye con el planteamiento de un nuevo artículo que regularía el derecho a un medio ambiente sano, adecuado y ecológicamente equilibrado, apto para el desarrollo y el bienestar de las personas y de la comunidad.

ABSTRACT: This paper intends to examine the shortcoming of the current formulation of the right to a healthy environment in the Chilean Constitution and, based on this analysis, to make a proposal that would cover the denomination of the right, its content and the definition of its scope. This latter analysis would be in light of legal doctrine, case law and the international human right law. The paper concludes with a proposal of a new provision that would regulate the right to a healthy, sound and adequate environment, ecologically balanced, suitable for the development and welfare of people and communities.

PALABRAS CLAVE: Derecho a vivir en un medio ambiente libre de contaminación, Derechos humanos, Desarrollo sostenible, Preservación de la naturaleza.

KEYWORDS: Right to a healthy environment, Human rights, Sustainable development, Conservation of nature.

* Trabajo recibido el 9 de marzo de 2016 y aprobado el 19 de octubre de 2016.

** Abogado (Chile), Doctor en Derecho (España), Magíster en Relaciones Internacionales (España), Máster en Derechos Humanos y Derecho Humanitario (Francia). Posdoctorado en el Max Planck Institute for Comparative Public Law and International Law (Heidelberg, Alemania). Profesor de Derecho Constitucional, Internacional, Ambiental y Derechos Humanos, Centro de Estudios Constitucionales de Chile, Universidad de Talca (Santiago, Chile). Director del Magíster en Derecho Constitucional del Centro de Estudios Constitucionales de Chile (Santiago, Chile). 


\section{INTRODUCCIÓN}

En este trabajo se aborda la pregunta acerca de cuáles son las deficiencias que plantea la formulación actual del derecho a vivir en un medio ambiente libre de contaminación a la luz de las normas y de la jurisprudencia, y, a partir de este punto, examinar cuál debiera ser el contenido de este derecho considerando el derecho internacional de los derechos humanos, el derecho comparado y la doctrina.

En cuanto al contenido normativo del derecho objeto de este estudio, nuestra hipótesis es que éste se encuentra determinado por la vida y la salud de las personas, el libre desarrollo de la personalidad relacionado con la dignidad humana, la preservación de la naturaleza y la conservación del patrimonio ambiental, cuya vulneración se produce cuando el entorno es afectado por hechos o actos que ponen en riesgo la vida o la salud de las personas o de las comunidades respectivas o atentan contra la calidad ambiental o el equilibrio ecológico. Aquello que sería característico de este derecho, y que lo diferenciaría del derecho a la vida o del derecho a la salud, es que aquí la afectación del ser humano se produce por el deterioro, la degradación o la polución del ambiente en niveles no tolerables por el individuo o la comunidad. Desde el punto de vista del contenido material del derecho, tanto la Constitución -interpretada armónica, finalista y axiológicamente, y complementada por el amplio plexo material del derecho internacional de los derechos humanos- como la ley, los reglamentos y los principios generales contribuyen a llenarlo ${ }^{1}$. La asunción precedente encuentra entre sus fundamentos la propia jurisprudencia del Tribunal Constitucional chileno ${ }^{2}$.

El objetivo principal de este trabajo es identificar las dificultades que plantea la formulación constitucional actual del derecho a vivir en un medio ambiente libre de contaminación y, a partir de esta identificación, proponer una nueva formulación y el contenido del derecho mencionado a la luz de la doctrina, la

\footnotetext{
1 A propósito del relevante rol que juega la jurisprudencia constitucional en el proceso de construcción de la constitución ambiental, vid. FoY VALENCIA, Pierre: "A propósito de la -mal denominada-constitución ecológica", en Revista Latinoamericana de Derecho y Políticas Ambientales, Año I, No 1, 2011, pp. 17-38, especialmente, p. 22

2 "[E]l convenio internacional no puede ser interpretado con prescindencia de la variada normativa nacional e internacional que regula la materia, particularmente en relación a la debida protección de la diversidad y del patrimonio fitogenético, en estricta concordancia con la obligación constitucional que se impone al Estado de velar para que el derecho a vivir en un medio ambiente libre de contaminación no sea afectado y a la vez que tutelar la preservación de la naturaleza”. Tribunal Constitucional de Chile: Requerimiento presentado por 17 senadores respecto de la constitucionalidad del Convenio Internacional para la Protección de Obtenciones Vegetales (UPOV-91) Boletín No 6426-10. Rol No 1988-11. Sentencia de fecha 24 de junio de 2011. Considerando $61^{\circ}$.
} 
jurisprudencia y el derecho internacional de los derechos humanos. Atendido el escenario nacional actual de debate en torno a un cambio constitucional, este estudio pretende concluir con una propuesta de reforma constitucional respecto del artículo 19 No 8 de la Constitución.

El examen del contenido del derecho resulta de gran relevancia, entre otras cosas porque este contenido determina una serie de características del mismo. Así, por ejemplo, el especial contenido del derecho a vivir en un medio ambiente libre de contaminación "le hace de interés colectivo"3.

En este estudio se abordará la primera parte del inciso primero del número 8 del artículo 19 de la Constitución, esto es, el derecho a vivir en un medio ambiente libre de contaminación. En cambio, no será objeto del mismo, al menos directamente, el resto de la preceptiva de dicho número. En el trabajo se ha utilizado el método dogmático y el de casos, especialmente para el análisis jurisprudencial.

El presente artículo se encuentra dividido en dos grandes partes: La primera parte examina el contenido actual del derecho a vivir en un medio ambiente libre de contaminación de acuerdo con las normas constitucionales y destaca las deficiencias que plantea a la luz de la doctrina y la jurisprudencia (I), y la segunda parte aborda el análisis de los contenidos que debieran ser considerados dentro de este derecho a la luz de los desarrollos contemporáneos, atendiendo a la doctrina, la jurisprudencia, el derecho comparado y el derecho internacional de los derechos humanos (II). El trabajo concluye con una propuesta de una nueva redacción, con reforzamiento de los contenidos, un nuevo artículo 19 No 8 de la Constitución.

\section{Determinación del Contenido actual del derecho en Chile}

En esta parte pretendemos identificar cuál es el contenido actual del derecho a vivir en un medio ambiente libre de contaminación de acuerdo con las normas constitucionales y destacar las deficiencias que plantea el mismo a la luz de la doctrina nacional y comparada, el derecho internacional y la jurisprudencia nacional.

\section{El contenido en función de la legislación actual y la jurisprudencia}

La formulación constitucional del derecho juega un rol relevante al momento de determinar su contenido. En el caso chileno, la propia redacción del artículo

3 Corte de Apelaciones de Valparaíso: Grupo de Acción Ecológica Chinchimén y otros. Recurso de Protección. Rol No 317-2008. Sentencia de fecha 8 de enero de 2009. Considerando $15^{\circ}$. 
19 No 8 inciso $1^{\circ}$ circunscribe el contenido del mismo. En nuestra opinión, la expresión "derecho a vivir en un medio ambiente libre de contaminación" pone el acento en las palabras "vivir" y "contaminación" ${ }^{4}$. De hecho, en la doctrina nacional, Guzmán sostiene que "la forma en que se puede alterar adversamente el ambiente no reconoce como única fuente la 'contaminación"”5. Por su parte,Silva Bascuñán ha señalado que "[l]as acciones que alteran o dañan la naturaleza no son siempre de tipo contaminante" 6 .

Una de las primeras observaciones que debería realizarse se refiere a la denominación constitucional escogida para este derecho. En efecto, la denominación que proporciona el artículo 19 No 8 de la Constitución -que a su vez revela también parte de su contenido- es el derecho a vivir en un medio ambiente libre de contaminación 7 . Como se verá a continuación, esta formulación constitucional plantea una serie de problemas.

En la doctrina y en el derecho comparado existen diversas denominaciones para referirse al derecho a vivir en un medio ambiente libre de contaminación, tales como el derecho a un medio ambiente sano, saludable, adecuado, ecológicamente equilibrado y apto para el desarrollo y el bienestar de las personas ${ }^{8}$. Entonces, se podría argumentar que otros términos, como el derecho a un medio ambiente sano o saludable, adecuado y ecológicamente equilibrado, apto para el desarrollo y el bienestar de las personas, resultan más convenientes por dos razones fundamentales. Primero, porque centran la preocupación del derecho en el medio ambiente. Segundo, porque amplían el ámbito de acción y, por lo tanto, de protección de este derecho, a formas de degradación del medio

4 Evans de la Cuadra señala a este respecto que el derecho a vivir en un medio ambiente libre de contaminación es consecuencia del derecho a la vida, a la integridad física y psíquica y del derecho a la salud. Evans DE la CuAdra (1999) p. 309.

5 "Por consiguiente, la manera de ejercer legítimamente este derecho no tiene relación con habitar en circunstancias exclusivamente exentas de contaminantes, sino en ausencia de factores que hagan idóneo su desarrollo y que van mucho más allá de situaciones configurativas de contaminación en sentido conceptual y legal estricto". GuZMÁn (2010), p. 38.

6 Silva (2008), p. 102.

7 " $[\mathrm{D}]$ entro de la Comisión de Estudios se utilizaron diversas fórmulas para expresar el derecho bajo examen, como fueron el derecho a un medio ambiente sano, el derecho a vivir en condiciones normales y el derecho a vivir en un medio ambiente libre de contaminación. Este último fue el que imperó en definitiva”. Guzmán Rosen, Rodrigo: Derecho ambiental chileno. Principios, instituciones, instrumentos de gestión. Santiago, Planeta Sostenible, 2012, p. 52.

8 Vid. Dellutri (2008), pp. 73-101. 
ambiente diversas de la contaminación, tal como es entendida esta última en el orden jurídico chileno.

Así, las primeras dificultades aparecen desde la propia enunciación del derecho en la Constitución. La formulación constitucional chilena de este derecho podríamos decir que es excepcionalísima en el derecho constitucional comparado. En este ámbito, se pueden encontrar diversas formas en las que se expresa este derecho, a saber: derecho a un ambiente sano o saludable (Constitución de Argentina, artículo 41); derecho a un medio ambiente equilibrado o ecológicamente equilibrado (Constitución de Costa Rica, artículo 50; Constitución de Paraguay, artículo 7; Constitución de Ecuador, artículo 14); derecho a un ambiente seguro para la vida y la salud (Constitución de Ucrania, artículo 50 inciso 1o); derecho a vivir en un medio ambiente benevolente o favorable (Constitución de la Federación Rusa, artículo 42); derecho a un ambiente que generalmente no sea dañoso a la salud o al bienestar y a un ambiente protegido (Constitución de Islas Vírgenes de los Estados Unidos, art. 29); el derecho a un medio ambiente tranquilo (Constitución de Montenegro, art. 23); derecho a un medio ambiente protegido, en beneficio de las generaciones presentes y futuras [Constitución de Sudáfrica, artículo 24 (b)]. Por cierto, la formulación constitucional chilena no se compadece con el desarrollo de este derecho en el ámbito del derecho internacional de los derechos humanos 9 . Por eso, una de nuestras primeras propuestas es cambiar la formulación constitucional del derecho por la siguiente: El derecho a un medio ambiente sano, adecuado, ecológicamente equilibrado y apto para el desarrollo y el bienestar de las personas.

Tal como precisa Cea Egaña, la idea inicial del derecho a vivir en un medio ambiente libre de contaminación "se encuentra en el proyecto de memorándum de intenciones sobre las metas y objetivos fundamentales en que debería inspirarse la nueva ley suprema”. El texto definitivo de este memorándum señalaba lo siguiente:

"El Estado reconocerá el libre acceso a la salud, considerándola como un todo indivisible en sus acciones para promoverla, protegerla, restituirla o revalidarla. Será de su deber, en cumplimiento de su fundamental misión de velar por la vida de los

9 "Artículo 11: Derecho a un Medio Ambiente Sano. 1. Toda persona tiene derecho a vivir en un medio ambiente sano y a contar con servicios públicos básicos; 2. Los Estados partes promoverán la protección, preservación y mejoramiento del medio ambiente". Protocolo Adicional a la Convención Americana sobre Derechos Humanos en materia de Derechos Económicos, Sociales y Culturales, Protocolo de San Salvador, 1988. 
ciudadanos, implícita en todas las Constituciones del mundo, consagrar normas que tiendan a evitar la contaminación del medio ambiente" 10 .

La regulación constitucional fue incorporada en el ordenamiento constitucional chileno en el artículo $1^{\circ} \mathrm{N}^{\circ} 18$ inciso $1^{\circ}$ del Acta Constitucional No 3 de $1976^{11}$. Posteriormente, estas regulaciones fueron trasladadas a la Constitución de 1980, al artículo 19 No 8. También es ampliamente conocido que, de la regulación original en la Constitución de 1980, se eliminó la última oración que se refería a que "la integridad territorial de Chile comprende la de su patrimonio ambiental"12. También se eliminó de la regulación original, en el marco del deber del Estado de tutelar la preservación de los recursos naturales, esta expresión final de "recursos naturales". En efecto, "[s]e reemplazó la expresión 'recursos naturales' por 'naturaleza', atribuyéndose a esta última un mayor alcance"13. Por último, también se sabe que de una propuesta inicial de incluir la referencia a "toda" contaminación, se eliminó la expresión "toda"14. Con esta supresión, lo que se pretendía era dejar claro que la Constitución no garantiza un medio ambiente libre de toda contaminación, porque ello sería virtualmente imposible, sino sólo aquella contaminación no tolerable o perjudicial para la salud o la vida de las personas ${ }^{15}$. En este sentido, Cea Egaña ha sostenido que "la Carta Fundamental no consagra el derecho a vivir en un medio ambiente exento de toda contaminación. Lo que ella asegura es sólo el derecho a vivir en un medio ambiente libre de aquella contaminación que sea nociva para la vida o la salud del hombre, como asimismo dañina para el ecosistema en que él desenvuelve normalmente su existencia"16. De estos razonamientos resultó el derecho fundamental, cuyo enunciado principal es el derecho a vivir en un medio ambiente libre de contaminación.

10 Cea Egaña, José Luis (1988), p. 325.

11 Evans de la Cuadra, Enrique (1999), p. 306; Cea Egaña, José Luis (1988), p. 331; Künsemüller, Carlos (1987), pp. 3-9; Carrasco, Diego (1996), pp. 103-125.

12 Künsemüller, Carlos (1987), pp. 3-9.

13 Künsemüller, Carlos (1987), pp. 3-9.

14 Evans de la Cuadra (1999), p. 308.

15 Cea Egaña, José Luis (1988), p. 327.

16 Cea Egaña, José Luis: Tratado de la Constitución de 1980. Características generales. Garantías constitucionales. Santiago, Editorial Jurídica de Chile, 1988, p. 332; Pérez L., María de los Ángeles: "Normas de calidad ambiental. Algunas consideraciones constitucionales y legales". Disponible en: http://www.cepchile. cl/dms/archivo_3759_1949/07_cap2maperez_libromambiente.pdf. Visitado el [27/1/2016]. 
A partir de esta breve reseña podríamos decir que existen dos tipos de deficiencias que fluyen desde el propio texto constitucional, pero que, en definitiva, ambas impactan en el contenido del derecho, que vamos a analizar a continuación.

\subsection{El carácter de derecho individual}

Por un lado, el derecho a vivir en un medio ambiente libre de contaminación se comprende como un derecho subjetivo sólo en cuanto derecho individual, lo que se concreta "en un ambiente que permita desarrollar la vida humana en condiciones normales"17. En efecto, el enunciado del artículo 19 de la Constitución comienza con la expresión de que 'la Constitución asegura a todas las personas' el derecho a vivir en un medio ambiente libre de contaminación. Este enunciado sumado a la orientación doctrinaria general de la Constitución, en el sentido de que consagra principalmente derechos individuales, dificulta la compresión de este derecho como un derecho social y fundamental y, por lo tanto, complica el esclarecimiento de su consecuente contenido. Cabe mencionar que algunos autores argumentan que "la regulación del medio ambiente en la Constitución de 1980 no escapó del influjo de la ideología neoliberal que inspiró la regulación de actividades económicas en la carta fundamental"18. En efecto, esta doctrina se ve reflejada cuando se afirma que "los derechos individuales, tales como la libertad personal y la libertad de expresión, son propiamente derechos subjetivos", mientras que las aspiraciones constitucionales o derechos sociales son simples expectativas y a pesar de su reconocimiento constitucional, ello "no las convierte por esa sola circunstancia en un verdadero derecho subjetivo ya que faltan a su respecto el sujeto pasivo y la determinación de la prestación" ${ }^{19}$. Y, además, bajo el prisma de los derechos fundamentales como derechos individuales, para poder ser considerado un verdadero derecho público subjetivo, el derecho a vivir en un medio ambiente libre de contaminación debe generar una obligación de no hacer, la obligación de no contaminar, esto es, una obligación de abstención ${ }^{20}$. Esto último es el resultado de la visión restringida de considerar al derecho a vivir en un medio ambiente libre de contaminación como un derecho individual en tanto derecho subjetivo. Con todo, concordamos con Bordalí cuando sostiene

17 Evans de la Cuadra (1999), p. 308.

18 Guiloff Titiun, Matías (2011), pp. 147-169.

19 Bertelsen Repetto, Raúl (1998), pp. 139-174.

20 Bertelsen Repetto, Raúl (1998), pp. 139-174, especialmente, p. 141. 
que este derecho presenta una estructura compleja que "va más allá del aspecto de un derecho negativo o defensivo de libertad, o más allá del mero aspecto de la contaminación, para comprender también la preservación de la naturaleza"21.

En resumen, desde esta perspectiva, dos son las grandes dificultades que enfrenta el derecho a vivir en un medio ambiente libre de contaminación. Por un lado, si se le califica como derecho social, correría el riesgo de quedar relegado al mero carácter de aspiración constitucionalmente reconocida, que implicaría una directriz para el Estado para realizar acciones positivas para prevenir o para mejorar la calidad ambiental 22 . Por otro, si se admite su carácter de derecho subjetivo, ello sería dentro de la esfera de los derechos individuales, que generan para el sujeto obligado sólo una obligación de no hacer, de abstención. En este sentido se pronuncia Künsemüller, cuando señala que "[e]l derecho a vivir en un ambiente exento de contaminación genera la obligación correlativa de no producir contaminación, que obliga a todos por igual, Estado y particulares"23. Como se puede apreciar, estas dos posiciones tradicionales juegan un rol relevante en la determinación del contenido del derecho. Es por ello que Evans de la Cuadra afirma que no entra en la consideración de este derecho "la preservación o cautela del patrimonio artístico y cultural y del paisaje". Y agrega que el derecho "cautela el bien jurídico de vivir en un ambiente libre de contaminación y no alcanza, por tanto, a otros valores ecológicos y de preservación o conservación del patrimonio natural o cultural" 24 . Sin embargo, en la jurisprudencia nacional se encuentran casos de vulneración del derecho a vivir en un medio ambiente libre de contaminación, entendida como alteración de la calidad ambiental, afectación del patrimonio ambiental o del equilibrio ecológico, por ejemplo, cuando una municipalidad ha llevado a cabo una poda de árboles en ciertos sectores de una ciudad. Por esta razón, nosotros debatimos en la segunda parte de este trabajo acerca de cuál debiera ser el contenido de este derecho a la luz de los desarrollos actuales ${ }^{25}$. Así, la Corte de Apelaciones de Valdivia sostuvo que "[a] juicio de esta Corte, ese resultado positivamente ofende la sensibilidad visual de cualquier

21 Bordalí Salamanca, Andrés (1999), pp. 7-26.

22 Bertelsen Repetto, Raúl (1998), pp. 139-174, especialmente, p. 141.

23 KünSEMÜller, Carlos (1987), pp. 3-9.

24 Evans de la Cuadra (1999), p. 310.

25 Por ejemplo, en el ámbito italiano, Rossi ha argumentado en torno a la evolución que ha experimentado el derecho al medio ambiente sano en los últimos decenios, y ha indicado que "el interés al medio ambiente no ha sido más tomado en consideración como un aspecto del derecho a la salud o a la salubridad del agua 
persona medianamente culta, esto es, produce efectivamente un agravio psicológico, una incomodidad, una desazón, compasión o tristeza, o directamente una indignación, sea ésta preferentemente estética, horticultural o ecológica" 26.

\subsection{La intima conexión con la vida y la salud y el enfoque en la contaminación}

Por otro lado, la especial formulación del derecho pone el énfasis en dos palabras del texto, a saber: "vivir" y "contaminación”. En primer lugar, "vivir" refleja la idea de que la preocupación inicial por este derecho se encontraba estrechamente vinculada a la vida y la salud de las personas en relación con el entorno ${ }^{27}$. “¿Qué sentido tiene el derecho a la vida si dejan de existir las condiciones ambientales necesarias para que el hombre pueda seguir viviendo sobre la tierra?", se preguntaba el profesor Valenzuela en $1977^{28}$. Por lo tanto, el acento está puesto en el derecho de las personas a vivir en un determinado entorno. Se trata de un derecho íntimamente conectado con la vida y la salud de las personas. Como efecto de su regulación como derecho individual y del diseño de la acción judicial constitucional que lo ampara (artículo 20 inciso $2^{\circ}$ de la Constitución chilena), este derecho sólo protegería a aquellas personas afectadas por la contaminación del medio ambiente, pero no a otros que no puedan demostrar un perjuicio directo, mediato e inmediato. También, en consecuencia, este derecho sólo protegería al individuo afectado con la contaminación y no a personas interesadas solidariamente en un bien superior como la preservación de la naturaleza y el equilibrio ecológico, por ejemplo, a raíz de una tala de especies nativas protegidas. En esta línea, Bordalí afirma que "el medio ambiente presenta un claro aspecto público y colectivo, es decir, interesa, sirve y afecta a toda una comunidad humana, y es en definitiva soporte para todos los demás derechos" 29 . Además, en la doctrina chilena se encuentran autores que discrepan de esta posición centrada en la vida y la salud de las personas, y afirman que hubo una voluntad explícita del cons-

o del aire sino que ha asumido una configuración propia, de valor primario, de derecho subjetivo". RossI (2015), pp. 3-25.

26 Corte de Apelaciones de Valdivia: Sentencia de fecha 21 de diciembre de 2007. Considerando 170; GuZMÁn (2012), p. 63.

27 Bordalí (1999), pp. 7-26, especialmente, p. 8.

28 Valenzuela (1977), pp. 215-243.

29 Bordalí (1998), pp. 43-54. 
tituyente "de proteger el entorno en sí mismo como valor jurídico esencial"30. Corral representa la otra vereda respecto de este punto, cuando señala que "[e]l medio ambiente no es un bien protegible en sí mismo, con un valor per se, sino en razón del hombre que desarrolla su existencia gracias a él"31. Bertelsen y, en menor medida, Bordalí coinciden con Corral ${ }^{32}$. Soto, Tallar y Ghiardo y Cea Egaña concurren en el argumento de que el derecho a vivir en un medio ambiente libre de contaminación se "configuraría como una ampliación de aquellos derechos consagrados en el art. 19 No 1 y 9, esto es, el derecho a la vida y a la integridad física y psíquica y el derecho a la protección de la salud"33. Por otra parte, estamos de acuerdo con Bordalí en el sentido de que el bienestar, la calidad de vida, la vida digna y el buen vivir serían bienes jurídicos protegidos en el derecho a vivir en un medio ambiente libre de contaminación ${ }^{34}$.

En segundo lugar, "contaminación", refleja la idea de los constituyentes de que la contaminación correspondía a la forma de vulnerar la vida de las personas por la vía de la afectación del medio ambiente. De hecho, Evans de la Cuadra afirma que "el bien jurídico cautelado por la Constitución como derecho humano es el ambiente libre de contaminación"35. Respecto de la contaminación, se plantea, primeramente, el problema de qué debe entenderse por contaminación, ya que la Constitución no la define. Como sostiene Guzmán Rosen, “[r]esulta capital saberlo, porque, como hemos anotado, de ello se desprenden consecuencias que finalmente nos afectan a todos en nuestra cotidianeidad. Es fundamental por lo mismo saber si la 'contaminación' corresponde a un simple hecho constatable por determinados instrumentos de la ciencia, lo es por el sentido común en el campo de las percepciones, o, al fin, si representa algo un poco más sofisticado" 36 . Si bien la expresión contaminación no se encuentra definida en la Constitución, sí está definida en la Ley de Bases del Medio Ambiente, en su artículo 2o letra c). De acuerdo con este precepto, se entiende por contaminación "la presencia en el

30 KÜNSEMÜlLER, Carlos (1987), pp. 3-9, especialmente, p. 6.

31 Corral Talciani, Hernán (1999), pp. 79-93, especialmente, p. 81.

32 Bertelsen (1999), pp. 7-26, especialmente, p. 13.

33 Soto (1992), p. 383; TAllar, F. y GHiardo, M.T. (1995), p. 14; Cea Egaña, aunque reconoce la íntima vinculación, afirma que se trata de derechos distintos. CEA (1988), p. 331.

34 Bordalí (1999), pp. 7-26, especialmente, p. 13.

35 Evans de la Cuadra (1999), p. 310.

36 GuZMÁn (2012), p. 52. 
ambiente de sustancias, elementos, energía o combinación de ellos, en concentraciones o concentraciones y permanencia superiores o inferiores, según corresponda, a las establecidas en la legislación vigente". La noción de contaminación, que está amparada por el ordenamiento jurídico chileno, se encuentra vinculada con la superación de ciertos niveles máximos o mínimos reglamentarios, establecidos en las normas de calidad ambiental, primarias o secundarias. De este modo, resulta fácil apreciar que la noción de contaminación circunscribe el ámbito de acción de este derecho, por cuanto "se desprende que dentro de su lógica interna hay contaminación sólo cuando existiendo una específica norma de calidad ambiental, primaria o secundaria, ésta se encuentre superada" 37 . Desde esta perspectiva, la protección del derecho se ve incluso más restringida si se toma en cuenta que para que proceda la tutela judicial efectiva del derecho a través de la acción de protección es necesario que el derecho "sea afectado por un acto u omisión ilegal" (artículo 20 inciso $2^{\circ}$ de la Constitución chilena).

Sin embargo, es posible imaginar otros casos de deterioro o degradación ambiental que no correspondan a episodios de contaminación estrictamente hablando, por ejemplo, la inundación de extensas zonas de terreno para la construcción de una represa, lo que alteraría el ecosistema local, provocaría la migración o desaparición de especies, sumergiría un pueblo declarado patrimonio de la humanidad y dejaría bajo agua un cementerio indígena y, además, una zona ancestralmente usada por ciertas culturas como área de rituales sagrados.

Una demostración de lo limitadora que puede resultar la expresión contaminación en la formulación constitucional se puede encontrar en la jurisprudencia constitucional. En efecto, el Tribunal Constitucional chileno ha confirmado la tesis de que "sólo existe contaminación cuando hay un canon jurídico concreto respecto de los contaminantes respectivos"38. Así, comenzó señalando que "jurídicamente contaminación no es cualquier impacto o alteración ambiental sino la situación que supera los parámetros ambientales establecidos”. Y continuó para concluir lo siguiente:

"De tal forma, mientras no se aprueben las normas de calidad ambiental respectivas que determinen objetivamente los parámetros dentro de los cuales es admisible en el ambiente una sustancia o elemento, no corresponde hablar de contaminación, a menos que se acredite inequívocamente la presencia en el ambiente de un contaminante, en

37 GUZMÁN (2012), p. 55.

38 GuZMÁN (2012), p. 55. 
términos tales que constituya un riesgo cierto a la vida, a la salud de la población, a la conservación del ambiente o la preservación de la naturaleza, o bien que exista una situación de pública e indiscutida notoriedad de la presencia gravemente nociva en el ambiente de un contaminante" 39 .

Además, no se debe olvidar que la contaminación a la que se refiere el artículo 19 No 8 de la Constitución es del medio ambiente. Por lo tanto, esta contaminación del medio ambiente se encuentra a su vez determinada por los elementos que componen este medio. Algunos autores sostienen una visión restringida del medio ambiente al que se refiere el artículo 19 No 8, porque "[s]i el medio ambiente es todo (recursos físicos, concepciones arquitectónicas, visiones paisajísticas, tradiciones culturales, costumbres), es prácticamente lo mismo decir que medio ambiente en definitiva y en rigor no es nada" 40 .

Como se puede apreciar, la sola redacción del artículo 19 No 8 de la Constitución genera dificultades y limita la expansión y desarrollo de este derecho, lo cual produce un impacto directo en las posibilidades de protección del mismo. Por esta razón, una de las primeras sugerencias es la reforma a la formulación constitucional del derecho por la redacción que se ha mencionado antes. Y, luego, se propone que se llene de contenido el derecho con las elaboraciones siguientes, ya sea directamente, a través de un proceso de reforma, o bien por medio de interpretaciones pretorianas. La parte que sigue de este artículo está dedicada a proponer cuál debería ser el contenido del derecho -que debería denominarse el derecho a un medio ambiente sano, adecuado, ecológicamente equilibrado y apto para el desarrollo y el bienestar de las personas- a la luz del derecho internacional de los derechos humanos, el derecho constitucional comparado, la jurisprudencia y la doctrina.

\section{EXAMEN DEL ALCANCE POTENCIAL DEL DERECHO}

En esta parte nos proponemos identificar los contenidos potenciales del derecho mencionado. Nosotros no queremos limitarnos al análisis literal de la norma, sino que quisiéramos extendernos al examen del aporte doctrinario y de la

39 Tribunal Constitucional de Chile: Requerimiento de inconstitucionalidad respecto del Decreto Supremo No 80, de 26 de agosto de 2006, del Ministerio Secretaría General de la Presidencia, que "Establece la norma de emisión para molibdeno y sulfatos de efluentes descargados desde tranques de relaves al estero Carén". Rol No 577-06. Sentencia de fecha 26 de abril de 2007. Considerando $13^{\circ}$.

40 Corral (1996), pp. 143-177, especialmente, p. 155. 
jurisprudencia nacional, internacional y comparada, y del derecho internacional de los derechos humanos. Para estos efectos, habrá que complementar el tenor literal del artículo 19 No 8 inciso $1^{\circ}$ primera parte, y abrirse a la jurisprudencia y la doctrina para determinar un contenido actualizado de este derecho, de acuerdo al contexto internacional y comparado.

\section{Contenido vinculado a la vida y al desarrollo sustentable}

Como se sabe, un derecho comporta necesariamente tres elementos: un titular al que se confiere un poder, un contenido determinado -¿̨n qué consiste ese poder? - y una o varias personas a las cuales el derecho les impone una obligación positiva o negativa ${ }^{41}$. Cuando aludimos a la expresión 'contenido' de un derecho fundamental, nos referimos al ámbito de protección que abarca este derecho, intentando determinar en qué consiste y, en definitiva, cuál es su extensión. Todo ello se traduciría en acciones u omisiones exigibles al Estado y eventualmente a los particulares ${ }^{42}$. En este sentido, Bertelsen ha sostenido que "el contenido del derecho es sustancialmente la facultad, o un haz de facultades, de hacer o de disfrutar algo en libertad, exenta de interferencias o perturbaciones. Y la obligación correlativa al derecho, que pesa o recae sobre toda persona o autoridad, es una obligación de no hacer consistente en el deber de abstenerse de comportamientos lesivos al derecho que se garantiza, obligación que se incumple si los obligados actúan impidiendo o dificultando el legítimo ejercicio del derecho"43.

Debido a que se trata de un análisis de este derecho, principalmente, a la luz de la jurisprudencia chilena, en este trabajo se utilizará indistintamente el término derecho a vivir en un medio ambiente libre de contaminación así como el de derecho a un medio ambiente sano, saludable, adecuado o ecológicamente equilibrado. En todo caso, nosotros preferiremos un concepto más amplio, entendiendo que nos referiremos al derecho a un medio ambiente sano, adecuado, ecológicamente equilibrado y apto para el desarrollo y el bienestar de las personas ${ }^{44}$.

\footnotetext{
41 Rivero (1980), pp. 41-60, especialmente, p. 48.

42 "El contenido del derecho no es otra cosa que el comportamiento que el titular del derecho puede exigir que cumpla el otro sujeto." GUASTini (1993), pp. 237-250, especialmente, p. 239.

43 BerTELSEN (1998), pp. 139-174, especialmente, p. 140.

44 Esta noción de derecho a un medio ambiente sano ya ha sido utilizada por vía pretoriana. Vid. v. gr. Corte Suprema de Chile: Flores Tapia, Cristian y otros con Minera Los Pelambres. Sentencia de reemplazo. Rol No 12938-2013. Sentencia de fecha 21 de octubre de 2014. Por su parte, la noción de derecho a un medio ambiente adecuado ha tenido recepción tanto en la jurisprudencia como en la doctrina
} 
El mejor punto de partida para examinar el contenido del derecho a vivir en un medio ambiente libre de contaminación es la Declaración de Estocolmo de 1972, cuya formulación de este derecho, en el principio 1, reza como sigue: "El hombre tiene derecho fundamental a la libertad, la igualdad y el disfrute de condiciones de vida adecuadas en un medio ambiente de calidad tal que le permita llevar una vida digna y gozar de bienestar, y tiene la solemne obligación de proteger y mejorar el medio ambiente para las generaciones presentes y futuras".

\subsection{Las afectaciones a la vida digna, la calidad de vida y el bienestar de las personas}

El amparo constitucional del derecho a vivir en un medio ambiente libre de contaminación y la razón fundamental por la cual se otorga protección constitucional al medio ambiente "sólo puede entenderse bajo la premisa que a partir de él se desarrolla toda forma de vida" ${ }^{4}$. La doctrina extranjera ha entendido que el derecho a la vida es el centro del derecho fundamental mencionado, ya que "solamente aquellos que posean vida, e incluso más, vida con calidad y salud, tendrán las condiciones para ejercer los demás derechos humanos" 46 . Y, además, se ha comprendido pretorianamente que la protección constitucional del medio ambiente apunta a garantizar "el respeto a la vida en su más amplio concepto" 47. Si bien resulta evidente que la vida biológica forma parte del contenido protegido por este derecho, también el ámbito amparado por el mismo se extendería a una noción más amplia de vida. En este sentido, resulta interesante la apreciación del Tribunal Constitucional en cuanto a que el medio ambiente involucra directamente la calidad de vida de las personas como parte del contenido del derecho fundamental que lo protege ${ }^{48}$. En esta línea, Canosa ha señalado que "[e]l medio

nacional. Vid. Guzmán (2010), p. 38; Bordalí (1999), pp. 7-26; Por otro lado, la noción de derecho a un medio ambiente ecológicamente equilibrado es usada en el derecho comparado. Vid. SERRA ReIS, Claudean: "Tutela constitucional ao bem jurídico ambiental e a PEC 341/09". Disponible en: http:// www.webartigos.com/artigos/tutela-constitucional-ao-bem-juridico-ambiental-e-a-pec-341-09/43136/. Visitado el 29/12/2015.

45 Corte Suprema de Chile: Central Termoeléctrica Campiche. Recurso de Protección. Rol No 1219-2009. Sentencia de fecha 22 de junio del 2009. Considerando $10^{\circ}$.

46 Antonietti (2011), pp. 204-216, especialmente, p. 214.

47 Corte de Apelaciones de San Miguel: Requena Berendique, Gloria y otros contra Kimica Chile Limitada y otro. Recurso de Protección. Rol o 297-2010. Sentencia de fecha 18 de febrero de 2011. Considerando 9º

48 Sentencia del Tribunal Constitucional, Rol No 2386, voto disidente, considerando $36^{\circ}$. 
ambiente es un bien colectivo de disfrute individual y general a un tiempo. La resultante de proteger este bien, y otros, es la calidad de vida" ${ }^{\prime 9}$.

Por esta razón, a continuación nos proponemos examinar el sentido y alcance de la noción de vida digna, de calidad de vida, de bienestar y de buen vivir, para comprender el alcance potencial de la protección del medio ambiente en este ámbito.

\section{a) Vida digna}

En cuanto al primer concepto, a nuestro modo de ver y en este contexto de examen del contenido del derecho a vivir en un medio ambiente libre de contaminación, cabe incorporar también la noción de vida digna. Este último concepto ha encontrado su desarrollo precisamente en el ámbito latinoamericano, fundamentalmente gracias a las enseñanzas de la Corte Interamericana de Derechos Humanos (en adelante, la Corte IDH). En este sentido, nuestra propuesta es que formaría parte del contenido del derecho no sólo la protección de la vida biológica de individuos, comunidades y pueblos y la salud de la población, sino que, además, habría que incluir el hecho de que el medio ambiente, su calidad, sus condiciones, sus elementos, debería permitir, asegurar una vida digna, con plena aplicación del principio de igualdad y de prohibición de la discriminación ${ }^{50}$. En esta línea, en el conocido caso de los Niños de la Calle, la Corte IDH argumentó en torno a la miseria en la que se desenvuelven los niños del caso, e indica que esta situación los priva de las condiciones mínimas de vida digna y les impide el pleno y armonioso desarrollo de su personalidad, "a pesar de que todo niño tiene derecho a alentar un proyecto de vida", cuyo cuidado es un deber para los poderes públicos ${ }^{51}$. Esta última noción, la de proyecto de vida, íntimamente vinculada con el principio de vida digna, contenido en el artículo 4 de la Convención Americana sobre Derechos Humanos (en adelante, la CADH), es también desarrollado en el conocido caso Loayza Tamayo. En este contexto, el daño en el proyecto de vida es diferente al daño emergente y al lucro cesante, en el sentido de que éste se refiere a la realización integral de la persona -tanto

49 CANOSA (1996), pp. 73-109, especialmente, p. 79.

50 "La pobreza y la inequidad social son otras fuerzas motrices importantes que influyen en el estado del medio ambiente en que vive la gente. Por ejemplo, la marginación de las minorías y las desigualdades por prejuicios de género conducen a que determinados grupos sociales vivan en ambientes de pobreza”. BALDI (2005), pp. 9-16, especialmente, p. 12.

51 Corte IDH: Caso de los "Niños de la Calle" (Villagrán Morales y otros) vs. Guatemala. Fondo. Sentencia de 19 de noviembre de 1999. Serie C No 63, para. 191. 
material como espiritualmente- "considerando su vocación, aptitudes, circunstancias, potencialidades y aspiraciones, que le permiten fijarse razonablemente determinadas expectativas y acceder a ellas" 52 . En consecuencia, afirma la Corte IDH, “[e]l 'proyecto de vida' se asocia al concepto de realización personal, que a su vez se sustenta en las opciones que el sujeto puede tener para conducir su vida y alcanzar el destino que se propone" 53 .

La Corte IDH ha desarrollado en su jurisprudencia la noción de vida digna, a partir de lo dispuesto en el artículo 4.1. de la Convención Americana sobre Derechos Humanos. En este sentido, ha señalado que "[a]l no respetarse el derecho a la vida, todos los demás derechos desaparecen, puesto que se extingue su titular. En razón de este carácter fundamental, no son admisibles enfoques restrictivos al derecho a la vida. En esencia, este derecho comprende no sólo el derecho de todo ser humano de no ser privado de la vida arbitrariamente, sino también el derecho a que no se generen condiciones que le impidan o dificulten el acceso a una existencia digna" 54 . En particular, refiriéndose a una de las obligaciones que emanan de este derecho a la vida digna, señala que es la de "de generar las condiciones de vida mínimas compatibles con la dignidad de la persona humana y a no producir condiciones que la dificulten o impidan. En este sentido, el Estado tiene el deber de adoptar medidas positivas, concretas y orientadas a la satisfacción del derecho a una vida digna, en especial cuando se trata de personas en situación de vulnerabilidad y riesgo, cuya atención se vuelve prioritaria" 55 . Y, luego, los jueces interamericanos han agregado las fuentes jurídicas a partir de las cuales puede hacerse este examen. En efecto, indica que debe efectuarse a la luz del corpus juris internacional existente, esto es, "a la luz de lo expuesto en el artículo 4 de la Convención, en relación con el deber general de garantía contenido en el artículo 1.1 y con el deber de desarrollo progresivo contenido en el artículo 26 de la misma, y de los artículos 10 (Derecho a la Salud); 11 (Derecho

52 Corte IDH: Caso Loayza Tamayo vs. Perú. Reparaciones y Costas. Sentencia de 27 de noviembre de 1998. Serie C No 42, para. 147.

53 Corte IDH: Caso Loayza Tamayo vs. Perú. Reparaciones y Costas. Sentencia de 27 de noviembre de 1998. Serie C No 42, para. 148.

54 Corte IDH: Caso Comunidad Indígena Yakye Axa vs. Paraguay. Fondo Reparaciones y Costas. Sentencia 17 de junio de 2005. Serie C No 125, para. 161; Cfr. NASH, Claudio: "Reseña de Jurisprudencia de la Corte Interamericana de Derechos Humanos”, en Anuario de Derechos Humanos, 2006, pp. 139-155, especialmente, p. 145.

55 Corte IDH: Caso Comunidad Indigena Yakye Axa vs. Paraguay. Fondo Reparaciones y Costas. Sentencia 17 de junio de 2005. Serie C No 125, para. 162. 
a un Medio Ambiente Sano); 12 (Derecho a la Alimentación); 13 (Derecho a la Educación) y 14 (Derecho a los Beneficios de la Cultura) del Protocolo Adicional a la Convención Americana en materia de Derechos Económicos, Sociales y Culturales, y las disposiciones pertinentes del Convenio No 169 de la OIT"56. Consecuentemente, nosotros consideramos que la extensión de la vida protegida en el derecho a vivir en un medio ambiente libre de contaminación alcanza a la vida digna, lo cual se encuentra íntimamente interrelacionado con el derecho a disfrutar de un entorno que asegure la mejor calidad de vida posible y el bienestar para el pleno desarrollo de la persona y la comunidad.

\section{b) Calidad de vida}

En cuanto a la calidad de vida, la Organización Mundial de la Salud (en adelante, la OMS) en 1994 propuso una definición de consenso: "Percepción del individuo sobre su posición en la vida en el contexto de la cultura y sistema de valores en el cual él vive, y en relación con sus objetivos, expectativas, estándares e intereses" 57.

En esta línea, Schwartzmann ha señalado que "[e]s claro que calidad de vida es una noción eminentemente humana que se relaciona con el grado de satisfacción que tiene la persona con su situación física, su estado emocional, su vida familiar, amorosa, social así como el sentido que le atribuye a su vida, entre otras cosas" 58 .

En la perspectiva ambiental de la calidad de vida, González sostiene que este concepto va mucho más allá que el de "nivel de vida" de una sociedad, pues "las necesidades que determinan una calidad de vida, no son solo materiales, sino también espirituales, y deben beneficiar no solo al hombre en su plenitud, sino también al ecosistema del cual depende. Este último, es la base misma de su existencia y ambos están ligados por una suerte común"59. Por su parte, Baldi y García señalan que "[d] esde una concepción integradora, la calidad de vida puede ser concebida como el resultado de las relaciones que establecen los individuos y

56 Corte IDH: Caso Comunidad Indigena Yakye Axa vs. Paraguay. Fondo Reparaciones y Costas. Sentencia 17 de junio de 2005. Serie C No 125, para. 161.

57 "What quality of life? The Whoqol Group. World Health Organization Quality of Life Assessment", in World Health Forum, Vol. 17, No 4, 1996, pp. 354-356.

58 SChWARTZMAnN, Laura: "Calidad de vida relacionada con la salud. Aspectos conceptuales", en Ciencia y Enfermería, Vol. IX, No 2, 2003, pp. 9-21, especialmente, p. 14.

59 GonZÁlez (2001), pp. 271-275, especialmente, p. 272. 
las comunidades con los elementos bióticos y abióticos del medio. Por otra parte, este concepto no puede percibirse desde un aspecto individual, sino que tiene que abordarse económica, social, cultural y ambientalmente, ya que toda evaluación subjetiva estará inmersa en un contexto sociohistórico determinado. A modo de ejemplo, la calidad del agua, del aire, de la tierra y el contacto con la naturaleza impactan directamente en la calidad de vida de las personas, afectando procesos básicos de salud" 60 . Más precisamente, Velarde-Jurado y Ávila-Figueroa han señalado que "[e]n su concepción más amplia, la calidad de vida recibe la influencia de factores como empleo, vivienda, acceso a servicios públicos, comunicaciones, urbanización, criminalidad, contaminación del ambiente y otros que conforman el entorno social y que influyen sobre el desarrollo humano de una comunidad"61.

De acuerdo con Canosa, en el contexto español, al Estado social se le encomienda la tarea de asegurar, para todos, condiciones vitales dignas que, en su conjunto, formarían la "calidad de vida". "Esa calidad de vida se nutriría de educación, protección de la salud, trabajo, vivienda, atención social de todo tipo y, también, de un medio ambiente adecuado"62. En la doctrina chilena, Silva Bascuñán ha afirmado que "[l] as acciones que alteran o dañan la naturaleza no son siempre de tipo contaminante, pero, por su especie, pueden causar la pérdida de la buena y sana calidad de vida de las personas, lo cual pone de relieve que es ése el bien jurídico protegido por el artículo 19 No 8"63. Esta afirmación ha sido respaldada por la jurisprudencia del Tribunal Constitucional chileno ${ }^{64}$.

Desde el punto de vista jurisprudencial, en el caso de Minera Los Pelambres, la Corte Suprema vinculó la calidad de vida con el principio de desarrollo sustentable, el cual es un principio jurídico cardinal en el ámbito medioambiental. En efecto, en este caso la Corte Suprema sostuvo que "la explotación de los yacimientos mineros, como el resto de los emprendimientos del sector industrial, debe estar en armonía con el hábitat y con los ecosistemas existentes y en concordancia con el desarrollo sustentable, que es el proceso de mejoramiento sostenido y equitativo de la calidad de vida de las personas, fundado en medidas apropiadas de conservación

60 BaLdi y García (2005), pp. 9-16, especialmente, p. 11.

61 Velarde y Ávila (2002), pp. 349-361.

62 Canosa (2006), pp. 151-215, especialmente, p. 153.

63 Silva (2008), p. 102.

64 Tribunal Constitucional de Chile: Requerimiento presentado por 17 Senadores respecto de la constitucionalidad del Convenio Internacional para la Protección de Obtenciones Vegetales (UPOV-91) Boletín No 6426-10. Rol No 1988-11. Sentencia de fecha 24 de junio de 2011. Considerando 56º 
y protección del medio ambiente, de manera de no comprometer las expectativas de las generaciones actuales y de las futuras" 65 . En este contexto, Bordalí señala que se daña "la calidad de vida de las personas cuando se altera o afecta la naturaleza" 66 .

En un caso donde se encontraba en discusión la legalidad urbanística y los principios del ordenamiento jurídico territorial, el Tribunal Constitucional menciona como deberes relevantes que le corresponden al Estado asegurar a todas las personas "el derecho a un nivel de vida adecuado". En efecto, en este preciso contexto, el Tribunal Constitucional indica que "en virtud del artículo $5^{\circ}$ de la Carta Fundamental, es deber del Estado respetar y promover derechos como el contenido en el artículo 25.1. de la Declaración Universal de Derechos Humanos, que reconoce que 'toda persona tiene derecho a un nivel de vida adecuado que le asegure, así como a su familia, la salud y el bienestar, y en especial la alimentación, el vestido, la vivienda, la asistencia médica y los servicios sociales necesarios' y el establecido por el artículo 11.1. del Pacto Internacional de Derechos Económicos, Sociales y Culturales, que reconoce ' (...) el derecho de toda persona a un nivel de vida adecuado para sí y su familia, incluso alimentación, vestido y vivienda adecuados, y a una mejora continua de las condiciones de existencia"”67.

\section{c) Bienestar}

El concepto de bienestar se encuentra vinculado con la definición de salud. La OMS afirma, en su Constitución, que "[1]a salud es un estado de completo bienestar físico, mental y social, y no solamente la ausencia de afecciones o enfermedades"68. Así, la salud refleja un cierto dinamismo. En este sentido, Pa-

65 Corte Suprema de Chile: Flores Tapia, Cristián y otros con Minera Los Pelambres. Sentencia de reemplazo. Rol No 12938-2013. Sentencia de fecha 21 de octubre de 2014. Considerando $25^{\circ}$.

66 Bordalí (1999), pp. 7-26, especialmente, p. 19.

67 Tribunal Constitucional de Chile: Requerimiento de inaplicabilidad por inconstitucionalidad presentado por Molinera del Norte S.A. respecto de los artículos 62 inciso segundo, y 160 del D.F.L. No 458, que aprueba la Ley General de Urbanismo y Construcciones, en los autos sobre recurso de casación en el fondo, caratulados "Molinera del Norte con I. Municipalidad de Antofagasta", de que conoce la Corte Suprema bajo el Rol No 16814-2013. Rol No 2643-2014. Sentencia de fecha 27 de enero de 2015. Considerando 23․

68 Constitución de la Organización Mundial de la Salud, Principios Básicos; Vid. Declaración de Alma Ata de 1978: "La salud, que es un estado de completo bienestar físico, mental y social, y no sólo la ausencia de enfermedad; es un derecho humano fundamental y que la consecución del nivel de salud más alto posible es un objetivo social prioritario en todo el mundo, cuya realización requiere la acción de muchos otros sectores sociales y económicos, además del sector sanitario". Conferencia InTERnaCional sobre Atención Primaria DE SAlud: Declaración de Alma Ata, URSS, 6-12 de septiembre de 1978. 
lomino, Grande y Linares agregan que la "salud es entendida como un proceso de adaptación; a partir del cual, salud y enfermedad son fenómenos relacionados con acontecimientos biológicos, la trayectoria personal, el entorno físico, social y cultural de las personas, en una relación que envuelve la vida de las personas"69.

Por último, la salud se encuentra amparada por el derecho a la salud, pero también, en cuanto bienestar, forma parte del contenido del derecho a vivir en un medio ambiente libre de contaminación. En este derecho, "el bienestar es realmente un bien jurídico nuclear, diferenciándolo, además, del derecho a la salud o a la vida. En un orden ascendente de gravedad, el bienestar es objeto de protección sin que sea necesario llegar a daños a la salud o a la propia vida"70. Por esta razón, Bordalí prefiere el término "medio ambiente adecuado", ya que "incluye el ambiente sin contaminación y una naturaleza preservada" 71 . En efecto, el Comité de Derechos Económicos, Sociales y Culturales, en su Observación General No 14, señala que "el derecho a la salud abarca una amplia gama de factores socioeconómicos que promueven las condiciones merced a las cuales las personas pueden llevar una vida sana, y hace ese derecho extensivo a los factores determinantes básicos de la salud, como la alimentación y la nutrición, la vivienda, el acceso a agua limpia potable y a condiciones sanitarias adecuadas, condiciones de trabajo seguras y sanas y un medio ambiente sano"72.

En definitiva, la noción de bienestar se vincula con el concepto de salud, que es amplio y multidimensional, al reflejar un estado que puede ser modificado de acuerdo con las perspectivas de vida y los roles sociales. Es decir, para evaluar globalmente la salud habría que incluir la noción de bienestar en el sentido de considerar inclusivamente sus condicionantes sociales, tales como educación, vivienda, condiciones de trabajo, medio ambiente, acceso al agua potable y saneamiento, etcétera ${ }^{73}$. Desde el punto de vista de la doctrina ambiental nacional, Guzmán y Bordalí coinciden en señalar que aquello jurídicamente amparado por el derecho consagrado en la Constitución, finalmente, "es el bienestar o la calidad de vida de las personas" 74 .

69 Palomino (2014), pp. 71-91, especialmente, p. 74.

70 Bordalí (1999) pp. 7-26, especialmente, p. 14.

71 Bordalí (1999), pp. 7-26, especialmente, p. 16.

72 Comité de Derechos Económicos, Sociales y Culturales: Observación General No 14. El derecho al disfrute del nivel más alto posible de salud. N.U. Doc. E/C.12/2000/4, 11 de mayo de 2000, para. 4.

73 Gezaine; De Lima Friche; Aguiar Lemos (2012), pp. 119-127.

74 GuZMán (2010), p. 67; Bordalí (1999), pp. 7-26. 
Al mismo tiempo, el bienestar humano se encuentra relacionado con el concepto de economía verde, esto es, aquella que no expone a las "generaciones futuras a riesgos ambientales y escasez ecológica significativa"75. Es decir, el bienestar, elemento de la salud, supone incluso condiciones económicas ambientalmente adecuadas, tanto para las presentes como para las futuras generaciones. Y, desde este punto de vista, bienestar se conecta con la noción de sustentabilidad ${ }^{76}$.

\section{d) Buen vivir}

Por último, en cuanto al concepto de buen vivir, se trata, por su origen, de una noción holística, que no hace diferencia entre el hombre y la naturaleza, sino que ambos forman parte de una misma realidad integrada y que prodiga un respeto profundo a la naturaleza como la fuente de la vida, la pacha mama ${ }^{77}$. Evidentemente, el buen vivir estaría vinculado con el estilo de vida y cosmovisión de los pueblos indígenas, sus tradiciones, usos y costumbres.

Este concepto de buen vivir se encuentra reconocido en los órdenes constitucionales comparados de algunos países de América Latina, por lo que resulta de gran relevancia para Chile tenerlo en cuenta. Por ejemplo, en la Constitución de Bolivia se consagra el principio de vivir bien, inter alia, en el artículo $8^{78}$. Por su parte, en la Constitución de Ecuador se incorpora la noción de buen vivir desde su preámbulo y lo inserta, por ejemplo, en el capítulo segundo, denominado "Derechos del buen vivir" (art. 12 y siguientes). Como indica Silva, los derechos del buen vivir constituyen los objetivos del desarrollo ${ }^{79}$. Y, por lo tanto, el buen vivir "es la piedra angular de la acción del poder público, así como de buena parte de la actividad privada" 80 . En este contexto, cabe señalar que el artículo 14 de la Constitución ecuatoriana consagra, en los siguientes términos, el derecho

\footnotetext{
75 PNUMA (2010), párr. 8.

76 FernándeZ y GutiérRez (2013), pp. 121-130.

77 "El equilibrio de los tres pachas se convierte, entonces, en el punto intermedio entre el sentir bien y el pensar bien, que se convierte en un actuar bien. Estos tres elementos relacionados y en armonía configuran el sumak kawsay, vivir bien”. SiLVA PORTERO (2008), pp. 111-154, especialmente, p. 119.

78 "Artículo 33. Las personas tienen derecho a un medio ambiente saludable, protegido y equilibrado. El ejercicio de este derecho debe permitir a los individuos y colectividades de las presentes y futuras generaciones, además de otros seres vivos, desarrollarse de manera normal y permanente". Constitución Política del Estado Plurinacional de Bolivia.

79 SILVA (2008), pp. 111-154, especialmente, p. 131.

80 Martínez (2012), pp. 708-722, especialmente, p. 714.
} 
a un medio ambiente sano: "Se reconoce el derecho de la población a vivir en un ambiente sano y ecológicamente equilibrado, que garantice la sostenibilidad y el buen vivir, sumak kawsay. Se declara de interés público la preservación del ambiente, la conservación de los ecosistemas, la biodiversidad y la integridad del patrimonio genético del país, la prevención del daño ambiental y la recuperación de los espacios naturales degradados".

Como se ha dicho, el concepto de buen vivir expresa una cosmovisión abarcadora de la integralidad de la vida, lo que incluye el entorno, esto es, la tierra, el territorio y el hábitat. Por esta razón, "el horizonte del vivir bien no sólo constituye una expectativa político social, es cuestión de vida" 81 . En esta línea, Silva ha sostenido que "[e]l 'buen vivir' en su formulación básica pone el acento en la relación armónica e integral entre los seres humanos y la naturaleza" 82 .

En Chile, donde entre un $8 \%$ y $10 \%$ de la población es indígena, esta noción de buen vivir encuentra un espacio legítimo de recepción, específicamente en el ámbito del derecho a vivir en un medio ambiente sano, adecuado y ecológicamente equilibrado, el desarrollo sustentable y la protección del medio ambiente. Recordemos que Chile ha ratificado el Convenio No 169 sobre pueblos indígenas y tribales de la Organización Internacional del Trabajo de $1989^{83}$ y ha participado activamente con su voto favorable en la adopción de la Declaración de las Naciones Unidas sobre los derechos de los pueblos indígenas de 200784. Estos dos instrumentos, que integran el ordenamiento jurídico nacional de conformidad con el artículo $5^{\circ}$ y demás disposiciones pertinentes de la Constitución chilena, sirven, de hecho, de fundamento normativo para justificar la aplicación del concepto de buen vivir en el ámbito del derecho a vivir en un medio ambiente sano, adecuado y ecológicamente equilibrado, del desarrollo sustentable y de la protección de los recursos naturales.

\subsection{El desarrollo sustentable}

El derecho a vivir en un medio ambiente libre de contaminación incluye el desarrollo dentro de la materia cubierta por éste. Cuando hablamos de desarrollo, ello implica incorporar el concepto de desarrollo sustentable y, por extensión, de

81 Palacín (2010), p. 78.

82 Silva (2008), pp. 35-44, especialmente, p. 36.

83 Ratificado por Chile el 15 de septiembre de 2008.

84 Vid., inter alia, art. 25 de la Declaración de las Naciones Unidas sobre los derechos de los pueblos indígenas. 
derecho al desarrollo (en este trabajo se alude a desarrollo sustentable o sostenible indistintamente).

La inclusión del desarrollo, entendido en el sentido anterior, encuentra su fundamento positivo en el artículo $1^{\circ}$ de la Constitución, que consagra el principio de dignidad humana y de igualdad (inciso $1^{\circ}$ ); el bien común como la finalidad del Estado (inciso 30); el deber del Estado de contribuir a crear las condiciones sociales que permitan a todos y a cada uno de los integrantes de la comunidad nacional su mayor realización espiritual y material posible (inciso $4^{\circ}$ ); el deber del Estado de dar protección a la población (inciso $5^{\circ}$ ), y de promover la integración armónica de todos los sectores de la Nación (inciso 5º. Además, encuentra su fundamento constitucional en el artículo $3^{\circ}$ de la Constitución, que consagra el principio del desarrollo equitativo y solidario intra e interregional. Este principio de solidaridad -principio rector del desarrollo nacional- se encuentra reiterado en el Capítulo XIV de la Constitución, referido a Gobierno y Administración Interior del Estado, en su artículo 115, cuando alude como principio básico al desarrollo armónico y equitativo, considerando criterios de solidaridad entre las regiones. Todo este entramado jurídico, al cual deben agregarse, además, las fuentes internacionales, por mandato del artículo $5^{\circ}$ de la Constitución chilena, corresponde a lo que nosotros podríamos denominar Constitución verde ${ }^{85}$.

Mediante una lectura conjunta del artículo 19 No 8 de la Constitución y el artículo $2^{\circ}$ letra ll) de la ley No 19.300 , se podría concluir que el medio ambiente y su protección incluyen no sólo elementos naturales y la preservación de la naturaleza, lo que implica extender la protección a los recursos naturales, el paisaje natural, las aguas, los bosques, el medio marino, etc., sino, además, incorporaría en su contenido elementos artificiales y socioculturales. Si esto es así, significa que el contenido del derecho a vivir en un medio ambiente libre de contaminación incluye el desarrollo sustentable, esto es, comprende el interés, individual y colectivo de la comunidad, jurídicamente tutelado por el uso racional de los recursos naturales, tanto para las generaciones presentes como futuras.

La ley No 19.300 define en su artículo 2o letra g) el desarrollo sustentable de la siguiente manera: "el proceso de mejoramiento sostenido y equitativo de la calidad de vida de las personas, fundado en medidas apropiadas de conservación y protección del medio ambiente, de manera de no comprometer las expectativas

85 Sobre la idea de una Constitución verde, Cfr. Vers une Constitution Verte de l'UE. Agosto de 2003. Disponible en: http://www.greenpeace.org/eu-unit/Global/eu-unit/reports-briefings/2007/5/vers-uneconstitution-verte-de.pdf. Visitado: [5/12/2016]. 
de las generaciones futuras". En consecuencia, no se trata de una noción extraña al ordenamiento jurídico chileno. Desde la perspectiva pretoriana, los jueces han afirmado la existencia de un interés general involucrado en el derecho a vivir en un medio ambiente sano, cuando han señalado que "la protección del medio ambiente no sólo es de interés de los que vivimos actualmente, sino también es de utilidad o provecho para las generaciones futuras" 86 . Así, el derecho a vivir en un medio ambiente libre de contaminación incluiría el derecho al desarrollo.

Desde la perspectiva de la fuente internacional, el derecho al desarrollo ha sido definido por el artículo $1^{\circ}$ de la Declaración sobre el derecho al desarrollo como sigue: "1. El derecho al desarrollo es un derecho humano inalienable en virtud del cual todo ser humano y todos los pueblos están facultados para participar en un desarrollo económico, social, cultural y político en el que puedan realizarse plenamente todos los derechos humanos y libertades fundamentales, a contribuir a ese desarrollo y a disfrutar de él. 2. El derecho humano al desarrollo implica también la plena realización del derecho de los pueblos a la libre determinación, que incluye, con sujeción a las disposiciones pertinentes de ambos Pactos internacionales de derechos humanos, el ejercicio de su derecho inalienable a la plena soberanía sobre todas sus riquezas y recursos naturales" 87 . El derecho al desarrollo incluye, por tanto, la protección y el ejercicio sobre las riquezas y recursos naturales. Ambos conceptos - derecho al desarrollo y derecho al medio ambiente- se potencian y retroalimentan a través de un equilibrio delicado, es por eso que Gómez Isa señala que "el derecho al desarrollo va a tener que contar necesaria e ineludiblemente con los condicionamientos medioambientales impuestos por el derecho a un medio ambiente sano y ecológicamente equilibrado" 88 . En este sentido, el punto de encuentro más intenso entre derecho al desarrollo y derecho a un medio ambiente sano, adecuado y ecológicamente equilibrado es el principio de sustentabilidad. Dicho de otro modo, el desarrollo al que se refiere el derecho respectivo es un desarrollo sustentable.

Desde el punto de vista jurisprudencial, la Corte Suprema ha reconocido ampliamente el principio de desarrollo sustentable y la noción de desarrollo de acuerdo con el enfoque de derechos humanos. Así, en el caso de Minera Los Pelam-

86 Corte de Apelaciones de Valparaíso: Grupo de Acción Ecológica Chinchimén y otros. Recurso de Protección. Rol No 317-2008. Sentencia de fecha 8 de enero de 2009. Considerando $15^{\circ}$.

87 Asamblea General: Declaración sobre el derecho al desarrollo. Resolución No 41/128, de fecha 4 de diciembre de 1986.

88 GÓMEZ (1999), pp. 282-283. 
bres, el máximo tribunal señaló que "[e]l desarrollo sin sustentabilidad no puede dañar impunemente el medio ambiente ni barrenar los derechos fundamentales de sus habitantes. Un progreso efectivo debe estar siempre en armonía con su entorno y constituir un genuino beneficio para todas las personas, preservando el bien común por sobre los intereses de algunos" 89 . Por su parte, los jueces constitucionales Fernández, Carmona y García, en un voto disidente en la sentencia rol No 2386-12, sostuvieron la sustentabilidad como principio conector entre el desarrollo y el medio ambiente. En efecto, los referidos jueces constitucionales afirmaron que "la pesca y las pesquerías, desde la economía, son una fuente de recursos, y visto desde el medio ambiente son un objeto a preservar en la búsqueda de equilibrios de sustentabilidad del desarrollo y de protección de las especies y ecosistemas del país. En tal sentido, es indudable que la rentabilidad económica de la explotación de estos recursos aparece necesariamente supeditada a que la utilización del recurso pueda hacerse sin menoscabo de las necesidades de futuras generaciones" 90 .

Así como la vida, lato sensu, y la salud de las personas forman parte del haz amparado por el derecho a vivir en un medio ambiente libre de contaminación, del mismo modo lo hacen la preservación de la naturaleza y la conservación del patrimonio ambiental y cultural.

\section{Contenido vinculado a la preservación de la naturaleza y a la conservación del patrimonio cultural}

El derecho a vivir en un medio ambiente libre de contaminación incluiría la preservación de la naturaleza, la protección del patrimonio ambiental y la conservación del patrimonio cultural. Este enfoque, a veces debatido, ha gozado de cierta recepción tanto en la doctrina como en la jurisprudencia constitucional y ordinaria, como se verá a continuación.

89 Corte Suprema de Chile: Flores Tapia, Cristián y otros con Minera Los Pelambres. Sentencia de reemplazo. Rol No 12938-2013. Sentencia de fecha 21 de octubre de 2014. Considerando 27º.

90 Tribunal Constitucional: Requerimiento presentado por un grupo de Senadores, que representan más de la cuarta parte de los miembros en ejercicio del Senado, para que se declare la inconstitucionalidad de los artículos $1^{\circ}$, numeral 19 y segundo transitorio del proyecto de ley que modifica, en el ámbito de la sustentabilidad de los recursos hidrobiológicos, acceso a la actividad pesquera industrial y artesanal y regulaciones para la investigación y fiscalización, la Ley General de Pesca y Acuicultura, contenida en la Ley No 18.892 y sus modificaciones, incluido en el Boletín No 8091-21. Rol No 2386-12. Sentencia de fecha 23 de enero de 2013. Voto en contra de los Ministros Francisco Fernández Fredes, Carlos Carmona Santander y Gonzalo García Pino. Considerando 48. 


\subsection{La preservación de la naturaleza}

La preservación de la naturaleza forma parte del contenido del derecho a vivir en un medio ambiente libre de contaminación, aun cuando también opera con autonomía propia como deber del Estado. Esto significaría que la preservación de la naturaleza forma parte integrante del derecho a un medio ambiente sano, adecuado y ecológicamente equilibrado, apto para el desarrollo y el bienestar de las personas. En consecuencia, podría cuestionarse la distinción tajante, en materia de medio ambiente, entre el derecho subjetivo y el deber para los poderes públicos, tal como lo propone una parte de la doctrina ${ }^{91}$. Para estos autores, la preservación de la naturaleza y la protección del medio ambiente no entran, ni pueden entrar, en la materia del derecho fundamental a vivir en un medio ambiente libre de contaminación. Por ejemplo, desde la perspectiva clásica, Soto Kloss ha sostenido que "[l]a preservación de la naturaleza, la protección o cuidado de los recursos naturales, el hábitat de los peces o las aves o los animales, es un deber jurídico puesto a la carga del Estado y de sus órganos que la ley cree al efecto, [...] pero ello nada tiene que ver ni se encuentra incluido en el derecho fundamental, subjetivo, individual, que se le reconoce a cada persona por el constituyente para vivir en un ambiente libre de contaminación”92. En esta línea, Evans de la Cuadra agrega que "[1]a tutela jurídica de la naturaleza es un encargo al Estado, pero no adquiere, en el texto constitucional, caracteres de un derecho reconocido o asegurado a los seres humanos" 93 .

Sin embargo, existen desarrollos teóricos y avances jurisprudenciales que podrían justificar una visión diversa. Desde el primer punto de vista, la explicación de la inclusión de la preservación de la naturaleza como contenido del derecho a vivir en un medio ambiente libre de contaminación podría comenzar con una referencia a las obligaciones positivas que emanan de los derechos humanos.

Como es habitual en materia de derechos humanos, el derecho a gozar de un medio ambiente libre de contaminación genera para los sujetos obligados,

91 La obligación de tutelar la preservación de la naturaleza "no se vincula con el derecho subjetivo", SiLVA (2008), p. 102. "La tutela jurídica de la naturaleza es un encargo al Estado, pero no adquiere, en el texto constitucional, caracteres de un derecho reconocido o asegurado a los seres humanos", EVANS DE LA CUADRA (1999), p. 310.

92 Soto (1993), pp. 22-27, especialmente, p. 24; En una orientación similar, vid. Bermúdez (2015), pp. 116-117. En un sentido contrario, vid. GUZMÁN (2012), pp. 62-63.

93 Evans de la Cuadra (1999), p. 308. 
tanto obligaciones negativas como positivas. En esta línea, la Corte IDH ha indicado que "no basta que los Estados se abstengan de violar los derechos, sino que es imperativa la adopción de medidas positivas, determinables en función de las particulares necesidades de protección del sujeto de derecho, ya sea por su condición personal o por la situación específica en que se encuentre" 94 . En otras palabras, las obligaciones positivas implican la obligación de hacer algo, o bien la obligación de adoptar medidas razonables y apropiadas para proteger y garantizar el derecho del individuo ${ }^{95}$.

Ya sabemos que los sujetos obligados pueden ser tanto el Estado como los particulares. Por ahora, quedémonos con el Estado. El derecho fundamental del artículo 19 No 8 genera para el Estado la obligación de abstenerse de interferir en el legítimo goce y ejercicio de dicho derecho y, al mismo tiempo, crea la obligación positiva de adoptar todas las medidas necesarias y adecuadas que apunten a proteger y preservar el pleno goce y ejercicio de tal derecho ${ }^{96}$. En efecto, Cancado Trindade sostiene que "el derecho a un medio ambiente saludable aparece como una extensión natural del derecho a la vida, en la medida que salvaguarda la vida humana misma bajo los dos aspectos de la existencia física y la salud de los seres humanos, y por otro lado de las condiciones dignas y la calidad de vida. Así, el derecho a un medio ambiente saludable comprende y amplía el derecho a la salud y el derecho a un nivel de vida adecuado. En suma, el derecho básico a

94 Corte IDH: Caso González y otras ("Campo Algodonero") vs. México. Excepción Preliminar, Fondo, Reparaciones y Costas. Sentencia de 16 de noviembre de 2009. Serie C No 205, para. 243.

95 AKandji-Kombe (2007), p. 7.

96 Las obligaciones positivas ante la Corte IDH: "La observancia del artículo 4, relacionado con el artículo 1.1 de la Convención Americana, no sólo presupone que ninguna persona sea privada de su vida arbitrariamente (obligación negativa), sino que además requiere que los Estados adopten todas las medidas apropiadas para proteger y preservar el derecho a la vida (obligación positiva), conforme al deber de garantizar el pleno y libre ejercicio de los derechos de todas las personas bajo su jurisdicción”. Corte IDH: Caso González y otras ("Campo Algodonero") vs. México. Excepción Preliminar, Fondo, Reparaciones y Costas. Sentencia de 16 de noviembre de 2009. Serie C No 205, para. 245; Las obligaciones positivas ante la Corte EDH: "Positive obligations on the State are inherent in the right to effective respect for private life under Article 8; these obligations may involve the adoption of measures even in the sphere of the relations of individuals between themselves. While the choice of the means to secure compliance with Article 8 in the sphere of protection against acts of individuals is in principle within the State's margin of appreciation, effective deterrence against grave acts such as rape, where fundamental values and essential aspects of private life are at stake, requires efficient criminal-law provisions. Children and other vulnerable individuals, in particular, are entitled to effective protection". E.C.H.R.: Case of Siliadin v. France (Application No 73316/01) Judgment, July 26th 2005; October 26 $6^{\text {th }}, 2005$, para. 79. 
la vida, incluyendo el derecho a la calidad de vida, implica obligaciones negativas así como positivas en favor de la preservación de la vida humana"97.

Como se ha sostenido, a partir del derecho subjetivo público -usando la terminología clásica- a vivir en un medio ambiente libre de contaminación, surgen para el Estado tanto obligaciones negativas como positivas. En cuanto a las primeras, el Estado tiene la obligación de no interferir en el pleno goce y ejercicio de este derecho. Respecto de las segundas, el Estado tiene la obligación de adoptar todas las medidas tendientes a asegurar el pleno goce y ejercicio del derecho mencionado, esto es, velar por que el derecho no sea afectado, tutelar la preservación de la naturaleza, asegurar la conservación del patrimonio ambiental, o sea, en una palabra, generar condiciones medioambientales mínimas y ecológicamente equilibradas compatibles con el goce pleno del derecho mencionado en el artículo 19 No 8 de la Constitución ${ }^{98}$. El incumplimiento de las obligaciones positivas por parte del Estado haría ilusorio y teórico el aseguramiento y satisfacción del derecho a vivir en un medio ambiente libre de contaminación ${ }^{99}$. En especial, este derecho se haría ilusorio frente al incumplimiento de las medidas positivas, "cuando se trata de personas en situación de vulnerabilidad y riesgo, que requieren una atención prioritaria y una protección especial” 100 .

Consecuentemente, desde la perspectiva de las obligaciones positivas, la protección del medio ambiente, la preservación de la naturaleza y la conservación del patrimonio ambiental formarían parte del contenido del derecho a vivir en un medio ambiente libre de contaminación.

En este contexto, interesa saber cuál ha sido la doctrina pretoriana a propósito de los recursos naturales existente en el medio ambiente y, más generalmente,

97 Cancado (1995), pp. 39-70, especialmente, p. 41.

98 En esta línea, Guzmán Rosen sostiene que la Constitución protege el ambiente y que "el ambiente se encuentra protegido doblemente, como derecho y en tanto tal, y esto último en la perspectiva de reclamar cuando se le afecta, y en la de exigir -por algún medio- que el Estado cumpla los deberes que en esta materia tiene a su cargo satisfacer". GUZMÁn (2010), p. 70.

99 "The Court notes that the applicants in the present case had the possibility of bringing legal proceedings; they availed themselves of it by suing the State in the Zagreb Municipal Court for damages in respect of their destroyed property. This of itself does not satisfy all the requirements of article $6 \$ 1$. It must also be established that the degree of access afforded under the national legislation was sufficient to secure the individual's "right to a court", having regard to the rule of law in a democratic society. The Court recalls that the Convention is intended to guarantee not rights that are theoretical or illusory but rights that are practical and effective". E.C.H.R.: Kutic vs. Croatia. Application No 48778/99. Judgment, June 1'st, 2002, para. 25.

100 Cfr. Corte IDH: Caso Comunidad Indígena Yakye Axa vs. Paraguay. Fondo Reparaciones y Costas. Sentencia 17 de junio de 2005. Serie C No 125, para. 162. 
acerca de la preservación de la naturaleza. Un buen punto de partida es indicar que los jueces constitucionales Fernández, Carmona y García parecen coincidir implícitamente con esta noción de obligaciones positivas que emanan, en este caso, del derecho a vivir en un medio ambiente libre de contaminación. En efecto, en un voto disidente en la sentencia rol No 2386-12, dichos jueces sostuvieron que "como bien colectivo que es, el Estado tiene un especial deber de tutelarlo, esto es, de 'amparar, guiar o defender' la preservación de la naturaleza. Por tanto, el deber estatal es activo y no se reduce a una tarea conservadora de prevención circunstancial sobre la misma"101.

Por su parte, desde la perspectiva de la jurisprudencia ordinaria, la Corte Suprema ha resaltado que con el derecho a vivir en un medio ambiente sano y libre de contaminación la sociedad está definiendo "la calidad del entorno deseable"102. De modo que ínsita en este derecho se encuentra la calidad del entorno o del ambiente, la cual debe ser adecuada, ecológicamente equilibrada y saludable. Además, la Corte Suprema de Chile ha considerado vulnerado el derecho a vivir en un medio ambiente libre de contaminación, ya que "dicha disposición impone al Estado la obligación de velar para que este derecho no se vea afectado; y, al mismo tiempo, tutelar la preservación de la naturaleza y esto último se refiere al mantenimiento de las condiciones originales de los recursos naturales, reduciendo al mínimo la intervención humana”. Y luego agrega que "los recurrentes tienen derecho, además, a instar por la preservación de la naturaleza y la conservación del patrimonio ambiental, actividad que obviamente no sólo compete a las personas que habitan cerca o en el lugar físico mismo en el que se estuviere desarrollando la explotación de recursos naturales y, desde ese aspecto, ellos también son afectados por la resolución recurrida"103.

Adicionalmente, el derecho a vivir en un medio ambiente libre de contaminación se extendería no sólo a la vida en el contexto del medio ambiente, sino

101 Tribunal Constitucional: Requerimiento presentado por un grupo de Senadores, que representan más de la cuarta parte de los miembros en ejercicio del Senado, para que se declare la inconstitucionalidad de los artículos $1^{\circ}$, numeral 19 y segundo transitorio del proyecto de ley que modifica, en el ámbito de la sustentabilidad de los recursos hidrobiológicos, acceso a la actividad pesquera industrial y artesanal y regulaciones para la investigación y fiscalización, la Ley General de Pesca y Acuicultura, contenida en la Ley No 18.892 y sus modificaciones, incluido en el Boletín No 8091-21. Rol No 2386-12. Sentencia de fecha 23 de enero de 2013. Voto en contra de los Ministros Francisco Fernández Fredes, Carlos Carmona Santander y Gonzalo García Pino. Considerando 37º. 102 Corte Suprema de Chile: Flores Tapia, Cristian y otros con Minera Los Pelambres. Sentencia de reemplazo. Rol No 12938-2013. Sentencia de fecha 21 de octubre de 2014.

103 Corte Suprema de Chile: Horvath Kiss, Antonio y otros con Comisión Nacional del Medio Ambiente. Recurso de Protección. Rol No 4658-96. Sentencia de fecha 19 de marzo de 1997. Considerando 13º. 
que, además, incluiría la preservación de la naturaleza misma. En este sentido, el voto por rechazar el requerimiento, en la sentencia rol No 2299-12, afirma lo siguiente:

"Que, de esta forma, es posible sostener que la pretensión de la requirente, Constructora Santa Beatriz, de oponerse a la ampliación de la Zona Típica del sector Costero de Isla Negra por coincidir con el terreno de su propiedad y en el que pretende efectuar una edificación colisiona, por un lado, con el derecho a vivir en un medio ambiente libre de contaminación, dentro del que se incluye la preservación de la naturaleza [...]. Es precisamente la necesidad de proteger un medio ambiente libre de contaminación junto con la preservación de la naturaleza, a que se refiere el numeral $8^{\circ}$ del artículo 19 constitucional, el fundamento de la facultad que se confiere al legislador para establecer limitaciones y obligaciones que favorezcan la conservación del patrimonio ambiental en razón de la función social de la propiedad (artículo 19 No 24, inciso segundo, de la Constitución)"104.

En el mismo sentido, se ha pronunciado un voto disidente en la sentencia rol No 2386-12 del Tribunal Constitucional, que declara que "el deber estatal de tutelar la preservación de la naturaleza se da en el marco del derecho a vivir en un medio ambiente libre de contaminación" 105.

Respecto a los elementos que componen el medio ambiente, principalmente aquellos como el agua, el suelo y el aire, el Tribunal Constitucional también los considera en relación a otras actividades humanas, y engloba a todos estos elementos en la noción de 'patrimonio ambiental'. Así, en el caso del agua, "[1] a conservación de los caudales de aguas y la adopción por parte del Estado de todas las medidas para evitar su agotamiento están comprendidas dentro de la

104 Tribunal Constitucional: Requerimiento de inaplicabilidad presentado por Constructora Santa Beatriz S.A. respecto de los artículos 29 y 30 de la Ley $N^{o} 17.288$, en los autos sobre recurso de protección, caratulados "Constructora Santa Beatriz S.A. con Ministerio de Educación y otro", de que conoce la Corte de Apelaciones de Santiago, bajo el Rol No 25.159-2012. Rol No 2299-12. Sentencia de fecha 29 de enero de 2014. Voto por rechazar el requerimiento. Considerando $16^{\circ}$.

105 Tribunal Constitucional: Requerimiento presentado por un grupo de Senadores, que representan más de la cuarta parte de los miembros en ejercicio del Senado, para que se declare la inconstitucionalidad de los artículos $1^{\circ}$, numeral 19 y segundo transitorio del proyecto de ley que modifica, en el ámbito de la sustentabilidad de los recursos hidrobiológicos, acceso a la actividad pesquera industrial y artesanal y regulaciones para la investigación y fiscalización, la Ley General de Pesca y Acuicultura, contenida en la Ley $N^{o} 18.892$ y sus modificaciones, incluido en el Boletín No 8091-21. Rol No 2386-12. Sentencia de fecha 23 de enero de 2013. Voto en contra de los ministros Francisco Fernández Fredes, Carlos Carmona Santander y Gonzalo García Pino. Considerando $38^{\circ}$. 
preservación del patrimonio ambiental, como uno de los elementos que comprende la función social de la propiedad"106. Además, la imposición de reglas restrictivas y de cautela en el otorgamiento de derechos de aprovechamiento de aguas, con el fin de alcanzar una racional ocupación de las aguas, "es coherente con el deber estatal de preservación de la naturaleza, reconocido en el artículo 19 numeral 8 inciso primero de la Constitución. Resulta claramente mejor protegido el bien común de todos y cada uno de los integrantes de la comunidad nacional, si tales reconocimientos de derechos se hacían ponderadamente"107. También en el ámbito del agua, la Corte Suprema, en el caso Los Pelambres, ha sostenido que "el vertimiento de desechos en el depósito de relaves de la denunciada contaminan las aguas, todo lo cual impide a los actores y al pueblo de Caimanes captar desde el pozo de agua potable rural las aguas que llegan de su descenso natural, y produce contaminación del recurso hídrico y deterioro del medio ambiente con el consiguiente perjuicio para la comunidad local", y agrega, "lo que ha creado un riesgo en el sustento de este recurso empleado en el consumo humano y como medio de producción, afectando la seguridad de la comunidad local" 108 .

Refiriéndose específicamente a los recursos naturales marinos renovables y la actividad económica, un voto disidente en la sentencia rol No 2386-12 del Tribunal Constitucional declara que deberá ser tenido en cuenta que "tratándose de recursos naturales renovables, debe primar un criterio mixto que compatibilice su disposición a tasas de explotación inferiores a la de su regeneración. En tal sentido, la naturaleza del recurso lo sitúa dentro de los deberes de protección propios del desarrollo sustentable y que el legislador ha definido como 'el proceso de mejoramiento sostenido y equitativo de la calidad de vida de las personas, fundado en medidas apropiadas de conservación y protección del medio ambiente, de manera de no comprometer las expectativas de las generaciones futuras' (artículo

106 Tribunal Constitucional, Sentencia rol No 1309, Requerimiento de inaplicabilidad por inconstitucionalidad del artículo 309 del Código de Aguas, 20 de abril de 2010, considerando $6^{\circ}$.

107 Tribunal Constitucional de Chile: Requerimiento de inaplicabilidad por inconstitucionalidad presentado por Agrícola San Isidro Limitada respecto de los artículos 129 bis 5, 129 bis 6 y 129 bis 9, del Código de Aguas, en los autos sobre recurso de reclamación, caratulados "Agricola San Isidro Limitada con Dirección General de Aguas", de que conoce la Corte de Apelaciones de Santiago, bajo el Rol No 3364-2014. Rol No 2693-14. Sentencia de fecha 13 de octubre de 2015. Considerando $24^{\circ}$.

108 Corte Suprema de Chile: Flores Tapia, Cristián y otros con Minera Los Pelambres. Sentencia de reemplazo. Rol No 12938-2013. Sentencia de fecha 21 de octubre de 2014. Considerandos $27^{\circ}$ y $28^{\circ}$. 
$2^{\circ}$, literal g), de la ley № 19.300)"109. De la misma forma, el examen del medio marino lo realiza a través de su vinculación con la actividad pesquera, enunciando -a propósito de los recursos marinos- que "la preservación de la naturaleza en el medio marino para la conservación y uso de los recursos vivos importa un mismo tipo de criterio aplicable en materia medioambiental, esto es, la necesidad de fijar un estándar cualitativo y cuantitativo para realizar dicha preservación" 110 . Cabe destacar aquí que el voto disidente de la sentencia pronunciada en el rol No 2386-12 recurre -correctamente a nuestro parecer- a la normativa internacional respecto de la protección de los recursos y el medio marino. Una de las normas de aplicación general más relevantes en esta materia es evidentemente la Convención de Naciones Unidas sobre derecho del mar de $1982^{111}$.

En cuanto a los recursos fitogenéticos, es decir, aquellos que se relacionan con la alimentación y que tienen origen vegetal, el Tribunal Constitucional declara que merecen la correspondiente protección, de manera que "el convenio internacional no puede ser interpretado con prescindencia de la variada normativa nacional e internacional que regula la materia, particularmente en relación a la debida protección de la diversidad y del patrimonio fitogenético, en estricta concordancia con la obligación constitucional que se impone al Estado de velar para que el derecho a vivir en un medio ambiente libre de contaminación no sea afectado y a la vez que tutelar la preservación de la naturaleza"112.

109 Tribunal Constitucional: Requerimiento presentado por un grupo de senadores, que representan más de la cuarta parte de los miembros en ejercicio del Senado, para que se declare la inconstitucionalidad de los artículos $1^{\circ}$, numeral 19 y segundo transitorio del proyecto de ley que modifica, en el ámbito de la sustentabilidad de los recursos hidrobiológicos, acceso a la actividad pesquera industrial y artesanal y regulaciones para la investigación y fiscalización, la Ley General de Pesca y Acuicultura, contenida en la Ley No 18.892 y sus modificaciones, incluido en el Boletín No 8091-21. Rol No 2386-12. Sentencia de fecha 23 de enero de 2013. Voto en contra de los ministros Francisco Fernández Fredes, Carlos Carmona Santander y Gonzalo García Pino. Considerando 47º. 110 Tribunal Constitucional: Requerimiento presentado por un grupo de senadores, que representan más de la cuarta parte de los miembros en ejercicio del Senado, para que se declare la inconstitucionalidad de los artículos $1^{\circ}$, numeral 19 y segundo transitorio del proyecto de ley que modifica, en el ámbito de la sustentabilidad de los recursos hidrobiológicos, acceso a la actividad pesquera industrial y artesanal y regulaciones para la investigación y fiscalización, la Ley General de Pesca y Acuicultura, contenida en la Ley No 18.892 y sus modificaciones, incluido en el Boletín No 8091-21. Rol No 2386-12. Sentencia de fecha 23 de enero de 2013. Voto en contra de los ministros Francisco Fernández Fredes, Carlos Carmona Santander y Gonzalo García Pino. Considerando 50.

111 A la que Chile adhirió el 25 de agosto de 1997.

112 Tribunal Constitucional de Chile: Requerimiento presentado por 17 senadores respecto de la constitucionalidad del Convenio Internacional para la Protección de Obtenciones Vegetales (UPOV-91) Boletín No 6426-10. Rol No 1988-2011. Sentencia de fecha 24 de junio de 2011. Considerando 61 ${ }^{\circ}$. 
Como ya se señaló, el artículo 19 No 8 de la Constitución consagra tanto un derecho como un deber para el Estado, concretamente el deber de preservar la naturaleza. Este último permite precisar de mejor forma el objeto de protección resguardado por la Constitución en esta norma. Aunque su desarrollo constitucional no es extenso, el Tribunal Constitucional ha elaborado su contenido: "El deber estatal de tutelar la preservación de la naturaleza se da en el marco del derecho a vivir en un medio ambiente libre de contaminación. Si bien está expresado como derecho subjetivo, resulta evidente la dimensión colectiva de este derecho (...). En tal sentido, se trata de un derecho que se caracteriza por su fuerte impronta de bien jurídico objetivo, por la protección conservacionista de determinados patrimonios naturales, por la tutela de intereses difusos y por su finalidad propia de proteger una titularidad nueva: las futuras generaciones"113. Asimismo, esta sentencia señala que "[1]a naturaleza es objeto de protección como un solo todo y su exclusividad como derecho subjetivo es simplemente inabordable" 114 .

Así, la vida es el interés cautelado por la disposición constitucional, siendo protegidos el medio ambiente y la preservación de la naturaleza en la medida en que afecten este derecho. En este sentido, la doctrina ha señalado que "[1]a naturaleza aparece así como un valor, un bien o patrimonio que pertenece a la colectividad y que debe ser mantenido y protegido para que lo puedan disfrutar y aprovechar las personas en el presente y en el futuro. Por ello, toda intervención en la naturaleza que implique un deterioro grave en su conservación y mantenimiento y que lleve, por ejemplo, a la extinción, de recursos naturales vivos o a la alteración significativa del paisaje, ha de ser combatida por toda la sociedad,

113 Tribunal Constitucional de chile: Requerimiento presentado por un grupo de senadores, que representan más de la cuarta parte de los miembros en ejercicio del Senado, para que se declare la inconstitucionalidad de los artículos $1^{\circ}$, numeral 19 y segundo transitorio del proyecto de ley que modifica, en el ámbito de la sustentabilidad de los recursos hidrobiológicos, acceso a la actividad pesquera industrial y artesanal y regulaciones para la investigación y fiscalización, la Ley General de Pesca y Acuicultura, contenida en la Ley No 18.892 y sus modificaciones, incluido en el Boletín No 8091-21. Rol No 2386-12. Sentencia de fecha 23 de enero de 2013. Voto en contra de los ministros Fernández, Carmona y García. Considerando $38^{\circ}$.

114 Tribunal Constitucional de chile: Requerimiento presentado por un grupo de senadores, que representan más de la cuarta parte de los miembros en ejercicio del Senado, para que se declare la inconstitucionalidad de los artículos $1^{\circ}$, numeral 19 y segundo transitorio del proyecto de ley que modifica, en el ámbito de la sustentabilidad de los recursos hidrobiológicos, acceso a la actividad pesquera industrial y artesanal y regulaciones para la investigación y fiscalización, la Ley General de Pesca y Acuicultura, contenida en la Ley No 18.892 y sus modificaciones, incluido en el Boletín No 8091-21. Rol No 2386-12. Sentencia de fecha 23 de enero de 2013. Voto en contra de los ministros Fernández, Carmona y García. Considerando 36º. 
representada por el Estado"115. La Corte Suprema coincide con que se trata de un valor de carácter superior del ordenamiento ${ }^{116}$.

Desde la perspectiva normativa, Cubillos señala como materias ambientales las siguientes: "a) El uso sustentable de los recursos naturales renovables (suelos, aguas, flora y fauna, bosques, áreas protegidas, recursos hidrobiológicos, etc.); b) La regulación de la contaminación, producto de emisiones, residuos, efluentes, ruidos, vibraciones, etc.; c) La protección y conservación de los recursos artificiales y socio-culturales (monumentos históricos, patrimonio arqueológico, urbanismo)"117. Lo anterior nos da una pista para responder a la pregunta de si el derecho a vivir en un medio ambiente libre de contaminación se extiende a todo el amplio espectro del medio ambiente.

Desde el punto de vista de la jurisprudencia nacional, la Corte Suprema ha sostenido que "medio ambiente, es decir, el patrimonio ambiental, la preservación de la naturaleza de que habla la Constitución y que ella asegura y protege, comprende todo lo que naturalmente nos rodea y que permite el desarrollo de la vida y tanto se refiere a la atmosfera, como al suelo y sus aguas, a la flora y fauna, todo lo cual conforma la naturaleza, con sus sistemas ecológicos de equilibrio entre los organismos y el medio en que viven"118. En consecuencia, todo lo que rodea al ser

115 Silva (2008), p. 102; Sentencia del Tribunal Constitucional, Rol No 1988-11, considerando 56º.

116 Corte de Apelaciones de Santiago: García Sabugal, Mario con Ministro de Agricultura. Recurso de Protección. Rol No 158-90. Sentencia de fecha 31 de mayo de 1990. Considerando 9º. Confirmada por la Corte Suprema: Rol No 15715. Sentencia de fecha 10 de julio de 1990.

117 Cubillos (2001), pp. 257-267, especialmente, p. 259. Por ejemplo, en el ámbito acústico, la jurisprudencia ordinaria ha señalado que "más allá de la necesaria tolerancia que debe existir por parte de los vecinos del local ES3, los que se encuentran obligados a soportar un cierto nivel de ruido, es evidente que la recurrida ES3 vulnera la garantía constitucional a vivir en un medio ambiente libre de contaminación de aquellos, puesto que de manera flagrante infracciona la norma D.S. No 146 de 1997, que regula el nivel de ruido que puede emanar de una fuente fija, cuyo establecimiento se encuentra enclavado en una zona residencial tip. 2". Corte de Apelaciones de Arica: Del Rosario Villanueva, Daniela y otros contra Marcello Pescetto Jacob. Recurso de Protección. Rol No 397-2010. Sentencia de fecha 1 de marzo de 2011. Considerando $12^{\circ}$.

118 Corte Suprema de Chile: Humberto Palza Carvacho con Dirección de Riego y Ministerio de Obras Públicas. (Lago Chungará Parque Nacional Lauca). Sentencia de 19 de diciembre de 1995; Corte Suprema de Chile: Horvath Kiss, Antonio y otros con Comisión Nacional del Medio Ambiente. Recurso de Protección. Rol No 4658-96. Sentencia de fecha 19 de marzo de 1997. Considerando 14º; Corte Suprema de Chile: Girardi Lavin y otros con Comisión Regional del Medio Ambiente de Magallanes y Antártica Chilena. Sentencia de fecha 21 de septiembre de 1999. Considerando 13º; Corte de Apelaciones de Valparaíso: Grupo de Acción Ecológica Chinchimén y otros. Recurso de Protección. Rol No 317-2008. Sentencia de fecha 8 de enero de 2009. Considerando 14․ Vid. Bronfman Vargas, Alan; Martínez Estay, José Ignacio; Núñez Poblete, Manuel: Constitución Política Comentada. Parte dogmática. Doctrina y Jurisprudencia. Santiago, Abeledo Perrot-LegalPublishing Chile, 2012, p. 201. 
humano formaría parte del campo de protección del medio ambiente. Entonces, el medio ambiente al que se refiere el artículo 19 No 8 de la Constitución no sólo comprende elementos artificiales y socioculturales, sino que también incluye la preocupación por el agotamiento de los recursos naturales, y la conservación del patrimonio ambiental ${ }^{119}$, razón por la cual el derecho fundamental "se extiende a la protección de los recursos naturales renovables" 120 .

En definitiva, el derecho a vivir en un medio ambiente libre de contaminación incluiría dentro de su contenido el deterioro de la naturaleza, la degradación del ecosistema, el agotamiento de los recursos naturales y, en general, cualquier desequilibrio ecológico. En este sentido, cabe recordar que la Comisión de Estudios de la Nueva Constitución de 1980 entendió que la "contaminación, expresión usada en la Constitución en forma genérica, comprende variadas formas o manifestaciones, como la suciedad creciente de las aguas, contaminación atmosférica sobre centros densamente poblados, producida básicamente por los desechos industriales; la contaminación acústica, los hedores que emiten determinados centros productivos, el agotamiento de los recursos naturales para la vida y el trabajo y, en general, todos los factores causales y las consecuencias negativas que forman parte del desequilibrio creciente en lo que era el sistema de normalidad ecológica"121.

\subsection{El patrimonio cultural}

El derecho a vivir en un medio ambiente libre de contaminación incluiría también el patrimonio cultural como elemento del medio ambiente. Esto es, el patrimonio cultural, lato sensu, integra el ámbito amparado por el derecho a vivir en un medio ambiente libre de contaminación. Este aspecto material del derecho ha sido reconocido tanto por la jurisprudencia ordinaria como constitucional.

En el caso de la jurisprudencia ordinaria, la Corte Suprema ha considerado dentro del derecho a vivir en un medio ambiente libre de contaminación la protección del valor paisajístico y turístico - por ende, del patrimonio cultural- de la comuna de Casablanca. En este sentido, se ha sostenido que "el Valle de Casablanca reúne una serie de características que han permitido el desarrollo de un producto

\footnotetext{
119 El artículo 2o letra b) de la ley No 19.300 define la conservación del patrimonio ambiental como "el uso y aprovechamiento racionales o la reparación, en su caso, de los componentes del medio ambiente, especialmente aquellos propios del país que sean únicos, escasos o representativos, con el objeto de asegurar su permanencia y su capacidad de regeneración".

120 Cubillos (2001), pp. 257-267, especialmente, p. 261.

121 Evans de la Cuadra, Enrique (1999), p. 311.
} 
de intereses especiales asociado a la actividad vitivinícola, cultural patrimonial tangible e intangible, todo lo cual se encuentra en la oferta turística de la Región de Valparaíso"122. En este contexto, frente al proyecto de instalar en la zona una planta faenadora de cerdos sin someterse previamente a un Estudio de Impacto Ambiental, la Corte sostuvo que "el proyecto puede influir negativamente en la magnitud del valor turístico de la zona de Casablanca, puesto que los olores que emanen de la planta obviamente tendrán una incidencia significativa en la decisión de los turistas de visitar o no la zona, si no se asegura debidamente el total control del efecto". Concluye la Corte Suprema que observa aquí "una amenaza al derecho de los recurrentes de vivir en un medio libre de contaminación, por lo que esta Corte brindará la cautela requerida, teniendo además en consideración que el someterse el proyecto a un Estudio de Impacto Ambiental permite asegurar el derecho antes aludido" 123 .

El valor paisajístico del medio ambiente también podría incluir lugares de gran belleza escénica que puedan resultar afectados por actos de las personas. De este modo, Guzmán ha sostenido que "el derecho a vivir en un ambiente adecuado, en clave constitucional, se encuentra agraviado cuando una determinada norma es infringida y a causa de la cual se produce un impacto ambiental autónomo, un fenómeno de contaminación en sentido estricto, o se configura un daño ambiental"124. A este último respecto, la Corte Suprema chilena ha indicado que "la calificación de daño ambiental significativo queda demostrada por tratarse de una corta ilegal de araucarias, especie declarada monumento natural, además del menoscabo que se generó al suelo y otros recursos forestales en un bosque de más de 150 años de antigüedad de gran belleza escénica" 125 .

La instalación de ferias libres, ferias de cachureos o ferias de las pulgas, como se las conoce, podría afectar el entorno, en este caso urbano, bajo ciertas circunstancias.

122 Como se ha dicho, esta posición de la Corte Suprema contrasta con la opinión de algunos autores que sostienen que "la Constitución no pretende cautelar en forma concreta otros bienes jurídicos, como las bellezas naturales, el paisaje, la intangibilidad y preservación de los recursos que la naturaleza pone a disposición de los hombres, las aguas, los bosques o la defensa de una política ecológica determinada”. EVANS DE la CuAdra, Enrique: Los derechos constitucionales. Tomo II. Santiago de Chile, Editorial Jurídica de Chile, 2a edición, 1999, p. 310.

123 Corte Suprema: Empresa Expo Pork Meat Chile S.A. Recurso de Protección. Rol No 5191-2010. Sentencia de fecha 18 de enero de 2011. Considerandos $5^{\circ}, 11^{\circ}, 13^{\circ}$.

124 GuZMÁn (2010), p. 62.

125 Corte Suprema de Chile: Consejo de Defensa del Estado con García Brocal, Julio y otro. Sentencia de reemplazo. Rol No 4033-2013. Sentencia de fecha 3 de octubre de 2013. Considerando No 15. 
La jurisprudencia ha reconocido que, como manifestaciones socioculturales, "históricamente las ferias libres constituyen una realidad de enorme significación"126. En este contexto, la Corte Suprema de Chile ha sostenido que "la instalación y funcionamiento de una feria libre, ocasiona en la práctica una contaminación acústica y biológica en el sector, alterando el medio ambiente normal existente, por los ruidos propios de los vehículos en que los comerciantes trasladan puestos y mercaderías; por la instalación de estos puestos; por el voceo normal de productos en alta voz; por la basura y desperdicios que se depositan en calzadas y veredas y por los desechos orgánicos que los comerciantes deben depositar en bolsas o recipientes al no contar con baños higiénicos"127. Cabe resaltar que en este caso el juez utiliza como parámetro "el medio ambiente normal existente". Por los antecedentes antes expuestos, la Corte concluye que los recurrentes han visto conculcado su derecho a vivir en un medio ambiente libre de contaminación.

Por otra parte, la jurisprudencia constitucional chilena ha incorporado el patrimonio cultural dentro del contenido del derecho a vivir en un medio ambiente libre de contaminación. Para la configuración de este patrimonio cultural, en ocasiones, ha recurrido al derecho internacional. ¿En términos generales, cuáles serían estas fuentes internacionales?

En primer lugar, cabe señalar que en 1972 se firmó en París, en el seno de la Unesco, la Convención sobre la protección del patrimonio mundial, cultural y natural ${ }^{128}$. El artículo 2 de esta Convención define el patrimonio natural incluyendo los siguientes tres elementos: 1) los monumentos naturales constituidos por formaciones físicas y biológicas o por grupos de esas formaciones que tengan un valor universal excepcional desde el punto de vista estético o científico; 2) las formaciones geológicas y fisiográficas y las zonas estrictamente delimitadas que constituyan el habitat de especies, animal y vegetal, amenazadas, que tengan un valor universal excepcional desde el punto de vista estético o científico; 3) los lugares naturales o las zonas naturales estrictamente delimitadas, que tengan un valor universal excepcional desde el punto de vista de la ciencia, de la conservación o de la belleza natural. Junto a este instrumento internacional, se puede mencionar la Convención para la protección de la flora, la fauna y las bellezas

126 Corte de Apelaciones de Valparaíso: Zernott Díaz, Emilio con Ilustre Municipalidad de Valparaíso. Recurso de Protección. Rol No 267-2006. Sentencia de fecha 4 de agosto de 2006. Considerando $8^{\circ}$.

127 Corte Suprema de Chile: Recurso de Protección. Rol No 117-1994. Sentencia de fecha 14 de octubre de 1994.

128 Ratificada por Chile el 20 de febrero de 1980. 
escénicas de América, celebrada en Washington el 12 de octubre de 1940, y que ha tenido intensa aplicación por los tribunales ${ }^{129}$.

Desde la perspectiva del patrimonio cultural, esta misma Convención incluye los monumentos (arquitectónicos, esculturales, pictóricos, inscripciones, cavernas), grupos de construcciones, arquitecturales e integradas en el paisaje y lugares como obras del hombre y de la naturaleza, incluidos los sitios arqueológicos que tengan un valor universal excepcional desde el punto de vista histórico, del arte o de la ciencia, estético, etnológico o antropológico ${ }^{130}$.

Con fecha 2 de noviembre de 2001 se adoptó la Declaración Universal de la Unesco sobre la Diversidad Cultural. El artículo 1 de esta importante declaración resalta el carácter de patrimonio común de la humanidad de la diversidad cultural y afirma que "[1]a cultura adquiere formas diversas a través del tiempo y del espacio. Esta diversidad se manifiesta en la originalidad y la pluralidad de las identidades que caracterizan a los grupos y las sociedades que componen la humanidad. Fuente de intercambios, de innovación y de creatividad, la diversidad cultural es tan necesaria para el género humano como la diversidad biológica para los organismos vivos. En este sentido, constituye el patrimonio común de la humanidad y debe ser reconocida y consolidada en beneficio de las generaciones presentes y futuras". Y, más adelante, en el artículo 4; vincula diversidad cultural con derechos humanos, señalando que "[l]a defensa de la diversidad cultural es un imperativo ético, inseparable del respeto de la dignidad de la persona humana”.

Luego, el 20 de octubre de 2005, la Unesco aprobó la Convención sobre la protección y promoción de la diversidad de las expresiones culturales ${ }^{131}$. El artículo 4

129 Las Partes en su Preámbulo expresaron: "Los Gobiernos Americanos deseosos de proteger y conservar en su medio ambiente natural, ejemplares de todas las especies y géneros de su flora y su fauna indígenas, incluyendo las aves migratorias, en un número suficiente y en regiones lo bastante vastas para evitar su extinción por cualquier medio al alcance del hombre". Ratificada por Chile el 23 de agosto de 1967; Vid. v. gr. Corte de Apelaciones de Santiago: García Sabugal, Mario con Ministro de Agricultura. Recurso de Protección. Rol No 158-90. Sentencia de fecha 31 de mayo de 1990. Confirmada por la Corte Suprema: Rol No 15715 . Sentencia de fecha 10 de julio de 1990.

130 El artículo 1 de esta Convención define como patrimonio cultural lo siguiente: “- los monumentos: obras arquitectónicas, de escultura o de pintura monumentales, elementos o estructuras de carácter arqueológico, inscripciones, cavernas y grupos de elementos, que tengan un valor universal excepcional desde el punto de vista de la historia, del arte o de la ciencia, - los conjuntos: grupos de construcciones, aisladas o reunidas, cuya arquitectura, unidad e integración en el paisaje les dé un valor universal excepcional desde el punto de vista de la historia, del arte o de la ciencia, - los lugares: obras del hombre u obras conjuntas del hombre y la naturaleza así como las zonas, incluidos los lugares arqueológicos que tengan un valor universal excepcional desde el punto de vista histórico, estético, etnológico o antropológico".

131 Ratificada por Chile el 13 de marzo de 2007. 
de esta Convención define la diversidad cultural como la "multiplicidad de formas en que se expresan las culturas de los grupos y sociedades. Estas expresiones se transmiten dentro y entre los grupos y las sociedades. La diversidad cultural se manifiesta no sólo en las diversas formas en que se expresa, enriquece y transmite el patrimonio cultural de la humanidad mediante la variedad de expresiones culturales, sino también a través de distintos modos de creación artística, producción, difusión, distribución y disfrute de las expresiones culturales, cualesquiera que sean los medios y tecnologías utilizados". Además, el artículo 2.6 de esta Convención destaca el principio de desarrollo sostenible como un principio rector y agrega que "[1]a diversidad cultural es una gran riqueza para las personas y las sociedades. La protección, la promoción y el mantenimiento de la diversidad cultural son una condición esencial para un desarrollo sostenible en beneficio de las generaciones actuales y futuras".

El 17 de octubre de 2003 se firmó en París la Convención para la salvaguarda del Patrimonio Cultural Inmaterial. En el preámbulo de esta Convención, los Estados partes destacan "la importancia que reviste el patrimonio cultural inmaterial, crisol de la diversidad cultural y garante del desarrollo sostenible". Además, en el artículo 2 se define el patrimonio cultural inmaterial y se señalan cuáles son sus manifestaciones principales.

Como se ha dicho, la jurisprudencia constitucional se ha apoyado en alguna de estas fuentes a propósito del patrimonio cultural y el medio ambiente. En efecto, en el caso rol No 2299-12 ante el Tribunal Constitucional, el voto por rechazar el requerimiento ha afirmado la idea del patrimonio cultural como elemento que compone el medio ambiente. En efecto, en el contexto de la protección del "medio ambiente libre de contaminación junto con la preservación de la naturaleza” frente a la pretensión del requirente de hacer valer su derecho de propiedad, los jueces constitucionales han incluido aspectos sociales y culturales, tales como la protección del patrimonio cultural inmaterial ${ }^{132}$. Dicho de otro modo, el patrimonio cultural -incluso el inmaterial-se integra como elemento del medio ambiente ${ }^{133}$.

132 Sobre la estrecha relación entre respeto y protección del medio ambiente y resguardo del patrimonio cultural inmaterial: "Sejnane, riche en filons d'argile, offre une variété de matières de base naturellement disponibles. De la préparation de l'argile pour le modelage, à la mixture des colorants végétaux pour la décoration jusqu'à l'utilisation de coquillage pour le polissage, tout est produit de l'environnement naturel immédiat. De l'extraction de la matière première au produit finit, tout se fait à la main!”. SEKIK, Nozha: “À propos du patrimoine immatériel : réflexion autour des savoir-faire des femmes en Tunisie”, en Cuadernos del Mediterráneo, No 14, 2010, pp. 280-284, p. 284.

133 Sobre una concepción del patrimonio cultural, Rodríguez ha sostenido que "implican una masa de bienes, valorables económicamente (o susceptibles de valoración económica, ya sea directa o indirecta), cuya 
Si el patrimonio cultural inmaterial ingresa dentro del ámbito de protección del medio ambiente y, por tanto, dentro de la esfera de protección que despliega el derecho a vivir en un medio ambiente libre de contaminación, con mayor razón debería entenderse incorporado el patrimonio cultural material ${ }^{134}$.

Para definir el patrimonio cultural inmaterial, los jueces constitucionales recurrieron correctamente al derecho internacional. En efecto, los jueces constitucionales Peña, Carmona, García y Hernández señalaron que:

"El patrimonio cultural inmaterial puede ser entendido como 'usos, representaciones, expresiones, conocimientos y técnicas, junto con los objetos y espacios culturales que les son inherentes, que las comunidades y en algunos casos los individuos reconozcan como parte integrante de su patrimonio cultural. Esta herencia se transmite de generación en generación, es recreada constantemente en función del entorno y la interacción con la naturaleza y la historia, e infunde un sentimiento de identidad y comunidad, promoviendo la diversidad cultural y la creatividad. Sus manifestaciones son: tradiciones y expresiones orales, incluido el idioma; artes del espectáculo; usos sociales, rituales y actos festivos; conocimientos y usos relacionados con la naturaleza y el universo, y técnicas artesanales tradicionales'. (Convención para la salvaguardia del patrimonio cultural inmaterial, aprobada por la Conferencia General de la Unesco, el 17 de octubre de 2003 y ratificada por Chile el 10 de diciembre de 2008)"135.

En realidad, toda la esfera del patrimonio cultural debería entenderse incorporada en este ámbito de protección constitucional. Y esta consideración del patrimonio cultural en la materia protegida por el derecho a vivir en un medio

envolvente es el servicio que prestan al desarrollo y enriquecimiento cultural personal. A ello debería añadirse la obligación, habida cuenta de la forma de adquisición por herencia de generaciones pasadas, de legarlo a las futuras. Esta acepción resulta tan sumamente poderosa en el lenguaje técnico que ha terminado por fagocitar los adjetivos que lo califican de histórico, artístico, cultural o natural. Así cada día resulta más frecuente leer la voz patrimonio sola (en textos dedicados a la gestión del patrimonio cultural sensu lato), dando a entender que se trata de las agrupaciones de bienes culturales (incluidas, recalco, el natural) reunidas en uno solo". Rodríguez Temiño, Ignacio: "Sobre el patrimonio cultural", en Sphera Pública, Revista de Ciencias Sociales $y$ de la Comunicación, número especial, 2010, pp. 75-117, especialmente, p. 80.

134 Vid. Convención sobre la protección del patrimonio mundial, cultural y natural, Unesco, 1972.

135 Tribunal Constitucional: Requerimiento de inaplicabilidad presentado por Constructora Santa Beatriz S.A. respecto de los artículos 29 y 30 de la ley $N^{o} 17.288$, en los autos sobre recurso de protección, caratulados "Constructora Santa Beatriz S.A. con Ministerio de Educación y otro", de que conoce la Corte de Apelaciones de Santiago, bajo el Rol No 25159-2012. Rol No 2299-12. Sentencia de fecha 29 de enero de 2014. Voto por rechazar el requerimiento. Considerando $16^{\circ}$. 
ambiente libre de contaminación se ve potenciada a través del principio de sustentabilidad ambiental ${ }^{136}$. Ya hemos dicho que la sustentabilidad ambiental -una expresión del principio de desarrollo sustentable- también se incorpora en el contenido del medio ambiente, cuya protección asegura la Constitución.

No es posible sino coincidir con la línea argumentativa del Tribunal Constitucional, al incluir dentro de la noción de medio ambiente el ámbito de la protección y conservación de los recursos artificiales y socioculturales relativos a ciertos atributos de las ciudades o de la historia del hombre, por ejemplo, la protección que se otorga a los restos arqueológicos ${ }^{137}$.

En este mismo ámbito cultural, ¿qué dice el Tribunal Constitucional chileno sobre la protección de los conocimientos tradicionales respecto de los recursos naturales, por ejemplo, sobre la protección de las plantas medicinales cuyo conocimiento es tradicional de los pueblos indígenas?

En cuanto a la vegetación originaria, y en relación a Convenio UPOV 91, el Tribunal Constitucional declara: "las variedades vegetales originarias y tradicionales que son propias de la biodiversidad chilena, de modo que éstas y las otras muchas variedades introducidas en el país y que se encuentran liberadas, pueden ser usadas y sembradas por pequeños agricultores y productores indígenas, sin ninguna restricción"138. Aun así, llama la atención que a pesar de concurrir en el fallo el ministro Viera-Gallo, la sentencia previene sobre un tema importante y no siempre recordado, como lo es la consulta a los pueblos originarios en esta materia. En palabras del Tribunal "el Convenio UPOV 91 no puede ser interpretado en ningún sentido que pudiera afectar tales conocimientos y prácticas tradicionales, los que dan origen a derechos que forman parte de la identidad cultural de las etnias originarias que el Estado de Chile debe respetar y promover por mandato constitucional y por compromisos internacionales derivados, entre otros instrumentos y tratados, del Convenio 169 de

136 "L'utilisation durable du patrimoine naturel et culturel est une exigence fondamentale du développement durable. En soutenant les systèmes traditionnels de protection de l'environnement et de gestion des ressources, nous pouvons contribuer à une meilleure durabilité des écosystèmes fragiles et à la préservation de la biodiversité, tout en réduisant ou empêchant la concurrence et les conflits autour de l'accès aux ressources naturelles et culturelles". BANDARIN, Francesco: "Le patrimoine culturel immatériel, au cœur du développement durable”, Doc. ADG/CLT/ART/2012/01, Unesco, París, july 21 th, 2012.

137 Cubillos (2001), pp. 257-267, especialmente, p. 260.

138 Tribunal Constitucional, Sentencia Rol No 1988-2011, Requerimiento presentado por 17 senadores respecto de la constitucionalidad del Convenio Internacional para la Protección de Obtenciones Vegetales (UPOV-91), 24 de junio de 2012, considerando $46^{\circ}$. 
la OIT"139. En consecuencia, se puede sostener que el medio ambiente como ámbito de protección incluye, por cierto, el resguardo de los conocimientos tradicionales. Un aspecto de este conocimiento tradicional es el conocimiento ecológico o ambiental tradicional el cual, de acuerdo con Berkes, Colding y Folke, ha sido definido como "un cuerpo acumulativo de conocimientos, prácticas y creencias que evoluciona a través de procesos adaptativos y es transmitido mediante formas culturales de una generación a otra acerca de las relaciones entre seres vivos, incluyendo los seres humanos, y de los seres vivos con su medio ambiente" 140 .

En este contexto, cabe recordar los compromisos internacionales que el Estado de Chile ha adquirido. En efecto, el Anexo II de la Declaración Universal de la Unesco sobre la Diversidad Cultural de 2001, titulado "Orientaciones principales de un plan de acción para la aplicación de la Declaración Universal de la Unesco sobre la Diversidad Cultural”, señala como obligación del Estado "[r] espetar y proteger los sistemas de conocimiento tradicionales, especialmente los de los pueblos indígenas; reconocer la contribución de los conocimientos tradicionales, en particular por lo que respecta a la protección del medio ambiente y a la gestión de los recursos naturales, y favorecer las sinergias entre la ciencia moderna y los conocimientos locales"141. Además, la Declaración de Estambul de 2002 destacó que las múltiples expresiones del patrimonio cultural inmaterial están "[p]rofundamente enraizadas en la historia local y en el entorno natural"142.

Por último, cabe agregar que el Tribunal Constitucional ha indicado que "la conservación del patrimonio ambiental del país y también de su patrimonio cultural, como fundamentos de la ampliación de la Zona Típica de que se trata, conduce inequívocamente a sostener que, en la especie, se ha configurado una limitación legítima al ejercicio del derecho de propiedad de Constructora Santa Beatriz, tanto en virtud de la función social de la propiedad como de la necesidad de proteger el patrimonio cultural de la Nación"143.

139 Tribunal Constitucional, Sentencia Rol No 1988-2011, Requerimiento presentado por 17 senadores respecto de la constitucionalidad del Convenio Internacional para la Protección de Obtenciones Vegetales (UPOV-91), 24 de junio de 2012, voto prevención ministro Viera-Gallo, considerando $3^{\circ}$.

140 BerKes y FolKe (2000), pp. 1251-1262, especialmente, p. 1252; ReYEs-García (2009), pp. 39-55.

141 Declaración Universal de la Unesco sobre la Diversidad Cultural, Anexo II, No 14.

142 "El patrimonio cultural inmaterial, espejo de la diversidad cultural". Declaración de Estambul, 16-17 de septiembre de 2002. III ${ }^{\text {a }}$ Mesa Redonda de Ministros de Cultura.

143 Tribunal Constitucional, Sentencia Rol No 2299-2012, Requerimiento de inaplicabilidad por inconstitucionalidad de los artículos 29 y 30 de la Ley No 17.288, deducido por Constructora Santa Beatriz S.A. 29 de enero de 2014, considerando $17^{\circ}$. 


\section{CONCLUSión}

El contenido normativo del derecho al desarrollo que se ha expuesto en este estudio mantiene siempre al ser humano en el centro de la preocupación del sistema de derechos. Evidentemente, en el caso del derecho fundamental a un medio ambiente sano, adecuado, ecológicamente equilibrado y apto para el desarrollo y el bienestar de las personas y de la comunidad, la centralidad del ser humano no puede desligarse de su desenvolvimiento en el entorno mismo y, al mismo tiempo, de su necesaria interdependencia y dependencia de la salubridad y adecuación del ambiente para su propia supervivencia.

Como se ha visto en este trabajo, la visión amplia del contenido del derecho fundamental a un medio ambiente sano, adecuado, ecológicamente equilibrado y apto para el desarrollo y el bienestar de las personas puede encontrar su respaldo tanto en un sector de la doctrina como en la jurisprudencia, tanto ordinaria como constitucional. Esta visión amplia implicaría considerar como parte integrante del contenido de este derecho, esto es, de la extensión material del poder que puede ejercer y exigir el o los titulares del mismo, a la vida y la salud de las personas, en su vertiente de vida digna, calidad de vida, bienestar y buen vivir. Junto a ello es indispensable la consideración del principio de desarrollo sustentable en conexión indivisible con el derecho al desarrollo dentro de la materia cubierta por el derecho a un medio ambiente sano, adecuado, ecológicamente equilibrado y apto para el desarrollo y el bienestar de las personas. Además, se incluye la preservación de la naturaleza y los recursos naturales y la conservación del patrimonio ambiental. Finalmente, se comprenden dentro del contenido de este derecho la protección del patrimonio cultural, en toda la extensión que el derecho constitucional y el derecho internacional le proporcionan a este patrimonio.

La revisión jurisprudencial que hemos realizado nos permitiría adelantar que este contenido del derecho ha sido acogido por la jurisprudencia del Tribunal Constitucional y de la Corte Suprema. Sin embargo, un aspecto relevante que resta por ver es si la jurisprudencia de los tribunales ambientales, cuyo principio de acción es el derecho fundamental a un medio ambiente sano, adecuado, ecológicamente equilibrado y apto para el desarrollo y el bienestar de las personas, aplicará este contenido amplio del derecho.

Por otra parte, esta conclusión nos lleva a constatar los defectos del reconocimiento constitucional del derecho que en nuestro sistema jurídico se denomina a vivir en un medio ambiente libre de contaminación. En efecto, la formulación del derecho en el artículo 19 No 8 de la Constitución debiera mejorarse y complementarse con los estándares que se han desarrollado y según el estándar internacional 
del Protocolo de San Salvador. En consecuencia, a partir de esta constatación, se propone la siguiente nueva redacción para el artículo 19 No 8:

"19 No 8: El derecho a un medio ambiente sano, adecuado y ecológicamente equilibrado, apto para el desarrollo y el bienestar de las personas y de la comunidad.

Cualquier persona, a título individual o en representación de una colectividad, está facultada para ejercitar las acciones legales en defensa del derecho al medio ambiente, sin perjuicio de la obligación de las instituciones públicas de actuar de oficio frente a los atentados contra el medio ambiente.

Asimismo, todos tienen el derecho a acceder a la información ambiental, el derecho a participar en la elaboración de las decisiones públicas que incidan en el medio ambiente y el derecho a acceder a la justicia ambiental, sin discriminación de ninguna especie.

El ejercicio de este derecho debe permitir a individuos y colectividades desarrollarse de manera integral.

Es deber del Estado velar para que este derecho no sea afectado y tutelar la preservación de la naturaleza, para el bienestar de las generaciones actuales y futuras. Los poderes públicos, así como los particulares, deben aplicar, como mínimo, el principio de precaución, de desarrollo sustentable y equidad intergeneracional.

Todos deben contribuir a la preservación y al mejoramiento del medio ambiente, y, en su caso, reparar integralmente los daños que han causado.

La ley podrá establecer restricciones específicas al ejercicio de otros derechos para proteger el medio ambiente".

\section{BiBLIOGRAFÍA CITADA}

AkandjI-Kombe, Jean Francois (2007): Positive obligations under the European Convention on Human Rights. Human Rights Handbooks No 7. Strasbourg, Council of Europe.

Antonietti Matthes, Rafael (2011): "O meio ambiente no sistema interamericano de protecao aos direitos humanos", en Revista da Faculdade de Direito de Sao Bernardo do Campo, Año 15, No 17, pp. 204-216.

AsAmblea General: Declaración sobre el derecho al desarrollo. Resolución No 41/128, de fecha 4 de diciembre de 1986.

BAldi López, Graciela y García Quiroga, Eleonora (2005): "Calidad de vida y medio ambiente. La psicología ambiental”, en Universidades, No 30, pp. 9-16. 
BANDARIN, Francesco (2012): "Le patrimoine culturel immatériel, au cœur du développement durable”, Doc. ADG/CLT/ART/2012/01, Unesco, París.

Berkes, Fikret; Colding, Johan; FolKe, Carl (2000): "Rediscovery of Traditional Ecological Knowledge as Adaptive Management", in Ecological Applications, Vol. 10, No 5, pp. 1251-1262.

Bermúdez Soto, Jorge (2015): Fundamentos de Derecho Ambiental. Valparaíso, Ediciones Universitarias de Valparaíso, 2a edición, reimpresión, pp. 116-117.

Bertelsen Repetto, Raúl (1992): "Facultades de Conaf y contaminación de aguas de un lago", en Revista Chilena de Derecho, Vol. 19, No 3, pp. 549-573.

BERTELSEN RepetTo, Raúl (1998): "El recurso de protección y el derecho a vivir en un medio ambiente libre de contaminación. Examen de quince años de jurisprudencia”, en Revista Chilena de Derecho, Vol. 25, No 1, pp. 139-174.

Bordalí Salamanca, Andrés (1998): "Constitución económica y protección del medio ambiente", en Revista de Derecho, Universidad Austral, Vol. 9, Número Especial, pp. 43-54.

Bordalí Salamanca, Andrés (1999): "El derecho fundamental a vivir en un medio ambiente adecuado: ¿Qué protege? ¿A quiénes protege?”, en Gaceta Jurídica, No 232, pp. 7-26.

Bronfman Vargas, Alan; Martínez Estay, José Ignacio; Núñez Poblete, Manuel (2012): Constitución Política comentada. Parte dogmática. Doctrina y jurisprudencia. Santiago, Abeledo Perrot-LegalPublishing Chile.

Cancado Trindade, Antonio Augusto (1995): "Environment and Development: Formulation and Implementation of the Right to Development as a Human Right”, en: Cancado Trindade, Antonio Augusto (Ed.): Derechos humanos, desarrollo sustentable y medio ambiente. San José, Instituto Interamericano de Derechos Humanos, 2a edición.

Canosa Usera, Raúl (1996): "Aspectos constitucionales del derecho ambiental", en Revista de Estudios Políticos (Nueva Época), No 94, pp. 73-109.

Canosa Usera, Raúl (2006): “¿Existe un verdadero derecho constitucional a disfrutar del medio ambiente?", en Anuario de Derechos Humanos, Nueva Época, Vol. 7, Tomo 1, pp. 151-215.

CARrasco, Diego (1996): "Derecho ambiental y a vivir en un medio ambiente libre de contaminación y recurso de protección en la Constitución Política del Estado, acciones populares ambientales", en Gaceta Jurídica, № 188, pp. 103-125.

Cea Egaña, José Luis (1988): Tratado de la Constitución de 1980. Características generales. Garantías constitucionales. Santiago, Editorial Jurídica de Chile. 
Corral Talciani, Hernán (1999): "El sistema de impacto ambiental y la responsabilidad civil por daño al medio ambiente", en Revista de Derecho Administrativo Económico, Vol. I, No 1, pp. 79-93.

Corral Talciani, Hernán (1996): "Daño ambiental y responsabilidad civil del empresario en la Ley de Bases del Medio Ambiente", en Revista Chilena de Derecho, Vol. 23, No 1, pp. 143-177.

Cubillos Prieto, Gonzalo (2001): "La extensión de la garantía constitucional referida al derecho a vivir en un medio ambiente libre de contaminación", en Navarro Beltrán, Enrique (Ed.): 20 años de la Constitución chilena 1981-2001. Editorial Jurídica Conosur Ltda., Santiago, pp. 257-267.

Dellutri, Rodrigo (2008): "El derecho humano al medio ambiente: el caso de los Pueblos autóctonos", en American University International Law Review, Vol. 24, Issue 1, pp. 73-101.

Evans de la Cuadra, Enrique (1999): Los derechos constitucionales. Tomo II. Santiago, Editorial Jurídica de Chile, 2a edición.

Fernández, Lilia y Gutiérrez, Mirella (2013): "Bienestar social, económico y ambiental para las presentes y futuras generaciones”, en Información Tecnológica, Vol. 24, No 2, pp. 121-130.

Foy Valencia, Pierre (2011): "A propósito de la-mal denominada-Constitución ecológica", en Revista Latinoamericana de Derecho y Políticas Ambientales, Año I, No 1, pp. 17-38.

GuASTINI, Riccardo (1993): "La garantía de los derechos fundamentales en la Constitución Italiana”, en Derechos y Libertades, Revista del Instituto Bartolomé de las Casas, Año 1, No 1, 1993, pp. 237-250.

Guiloff Titiun, Matías (2011): "El dilema del artículo 19 No 8 inciso 2o", en Revista de Derecho, Universidad Católica del Norte, Año 18, No 1, pp. 147-169.

Gómez IsA, Felipe (1999): "El derecho al medio ambiente y el derecho al desarrollo: hacia una necesaria vinculación", en Declaración de Bizkaia sobre el Derecho al Medio Ambiente. IVAP-Diputación Foral de Bizkaia, Bilbao, pp. 282-283. Goncalves da Costa Azevedo, Gezaine Priscila; De Lima Friche, Amélia Augusta; Aguiar Lemos, Stela Maris (2012): "Quality of Life and Self-Perception of Health of Patients from an Outpatient Clinic of Speech-Language Pathology and Audiology", in Revista da Sociedade Brasileira de Fonoaudiologia, Vol. 17, No 2, pp. 119-127.

GonZÁlez SiLVA, Francisco Javier (2001): ¿Es el derecho a vivir en un medio ambiente sano y adecuado, un derecho humano reconocido como tal? ¿Cómo 
construir su adecuada tutela jurídica?", en Revista Chilena de Derecho, Vol. 28, No 2, pp. 271-275.

Guzmán Rosen, Rodrigo (2012): Derecho ambiental chileno. Principios, instituciones, instrumentos de gestión. Santiago, Planeta Sostenible.

GuZMÁn Rosen, Rodrigo (2010): La regulación constitucional del ambiente en Chile. Santiago, Abeledo Perrot-LegalPublishing, 2a edición.

KÜNSEMÜller, Carlos (1987): "Protección legal del medio ambiente: qué enseñar, qué investigar. Legislación chilena: características, evolución. Interés por un derecho penal del entorno", en Gaceta Jurídica, Año XII, No 85, pp. 3-9.

Martínez Dalmau, Rubén (2012): "Vivir bien e innovación en el nuevo constitucionalismo: la Constitución ecuatoriana de 2008", en Actas del XV Encuentro de Latinoamericanistas Españoles. Congreso Internacional "América Latina: La Autonomía de una región". Madrid, Trama Editorial, CEEIB, pp. 708-722.

NASH, Claudio (2006): "Reseña de Jurisprudencia de la Corte Interamericana de Derechos Humanos", en Anuario de Derechos Humanos.

Palacín QuisPe, Miguel (2010): Buen vivir/Vivir bien. Filosofía, politicas, estrategias y experiencias regionales andinas. Lima, Coordinadora Indígena de Organizaciones Indígenas, Tercera Edición.

Palomino Moral, Pedro; Grande Gascón, María Luisa, y Linares Abad, Manuel (2014): "La salud y sus determinantes sociales: desigualdades y exclusión en la sociedad del siglo XXI", en Revista Internacional de Sociología, Vol. 72, extra 1, pp. 71-91.

Pérez L., María de los Ángeles (2016): “Normas de calidad ambiental. Algunas consideraciones constitucionales y legales". Disponible en: http://www.cepchile.cl/dms/archivo_3759_1949/07_cap2maperez_libromambiente.pdf. Visitado el [27/1/2016].

PNUMA (2010): Economia Verde: elementos de carácter general que pueden ser utilizados por los Ministros y Jefes de Delegación para el Intercambio sobre economía verde. Doc. N.U. UNEP/LAC-IG.XVII/4.

Reyes-García, Victoria (2009): "Conocimiento ecológico tradicional para la conservación: dinámicas y conflictos”, en Papeles, No 107, pp. 39-55.

Rivero, Jean (1980): Sur le droit du développement. Unesco, Doc. SS-78/Conf.630/ Supp. 2 citado por Gros Espiell, Héctor: "El derecho al desarrollo como un derecho de la persona humana”, en Revista de Estudios Internacionales, No 1, pp. 41-60. 
Rodríguez Temiño, Ignacio (2010): "Sobre el patrimonio cultural”, en Sphera Pública, Revista de Ciencias Sociales y de la Comunicación, número especial, pp. 75-117.

Rossi, Giampaolo (2015): “Diritto dell'ambiente e diritto dell'alimentazione”, en Revista Quadrimestrale di Diritto dell'Ambiente, No 1, pp. 3-25.

SEKIK, Nozha (2010): "À propos du patrimoine immatériel : réflexion autour des savoir-faire des femmes en Tunisie”, en Cuadernos del Mediterráneo, № 14, pp. 280-284, p. 284.

Silva Bascuñán, Alejandro (2008): Tratado de Derecho Constitucional. Tomo XII. Santiago de Chile, Editorial Jurídica de Chile.

Silva Portero, Carolina (2008): “Después del 'desarrollo': el 'buen vivir' y las perspectivas feministas para otro desarrollo en América Latina", en Umbrales. Revista del Postgrado Multidisciplinario en Ciencias del Desarrollo, No 18, pp. 35-44.

Silva Portero, Carolina (2008): “¿Qué es el buen vivir en la Constitución?”, en Ávila Santamaría, Ramiro (Ed.): La Constitución de 2008 en el contexto andino. Análisis desde la doctrina y el derecho comparado. Quito, Ministerio de Justicia y Derechos Humanos, pp. 111-154.

Serra ReIs, Claudean (2015): “Tutela constitucional ao bem jurídico ambiental e a PEC 341/09”. Disponible en: http://www.webartigos.com/artigos/tutelaconstitucional-ao-bem-juridico-ambiental-e-a-pec-341-09/43136. Visitado el 29/12/2015.

Sото Kloss, Eduardo (1993): "El derecho fundamental a vivir en un ambiente libre de contaminación: su contenido esencial”, en Gaceta Jurídica, No 151, pp. 22-27.

Soto KLoss, Eduardo (1992): "El comentario a la sentencia de la C. de Apelaciones de Copiapó de 22/06/92" (Recurso de Protección), en Revista de Derecho y Jurisprudencia y Gaceta de los Tribunales, Tomo LXXXIX, No 3.

SchWARTZMAnN, Laura (2003): "Calidad de vida relacionada con la salud. Aspectos conceptuales”, en Ciencia y Enfermería, Vol. IX, No 2, pp. 9-21.

TAllar, F. y GHIARDO, M.T. (1995): "Carácter de la normativa constitucional y legal sobre el medio ambiente”, en Gaceta Jurídica, núm. 175, 1995.

Valenzuela Fuenzalida, Rafael (1997): "El Derecho del entorno y su enseñanza”, en Revista de Derecho de la Pontificia Universidad Católica de Valparaíso, No 1, pp. 215-243.

Velarde-Jurado, Elizabeth y Ávila-Figueroa, Carlos (2002): "Evaluación de la calidad de vida”, en Salud Pública de México, Vol. 44, No 4, pp. 349-361. 


\section{JURISPRUDENCIA CITADA}

Corte de Apelaciones de Santiago: García Sabugal, Mario con Ministro de Agricultura. Recurso de Protección. Rol No 158-90. Sentencia de fecha 31 de mayo de 1990. Confirmada por la Corte Suprema: Rol No 15715. Sentencia de fecha 10 de julio de 1990 .

Corte de Apelaciones de Arica: Del Rosario Villanueva, Daniela y otros contra Marcello Pescetto Jacob. Recurso de Protección. Rol No 397-2010. Sentencia de fecha 1 de marzo de 2011.

Corte de Apelaciones de San Miguel: Requena Berendique, Gloria y otros contra Kimica Chile Limitada y otro. Recurso de Protección. Rol No 297-2010. Sentencia de fecha 18 de febrero de 2011.

Corte de Apelaciones de Valparaíso: Zernott Díaz, Emilio con Ilustre Municipalidad de Valparaíso. Recurso de Protección. Rol No 267-2006. Sentencia de fecha 4 de agosto de 2006.

Corte de Apelaciones de Valparaíso: Grupo de Acción Ecológica Chinchimén y otros. Recurso de Protección. Rol No 317-2008. Sentencia de fecha 8 de enero de 2009.

Corte IDH: Caso Loayza Tamayo vs. Perú. Reparaciones y Costas. Sentencia de 27 de noviembre de 1998. Serie C No 42.

Corte IDH: Caso de los "Niños de la Calle" (Villagrán Morales y otros) vs. Guatemala. Fondo. Sentencia de 19 de noviembre de 1999. Serie C No 63, para. 191.

Corte IDH: Caso Comunidad Indígena Yakye Axa vs. Paraguay. Fondo Reparaciones y Costas. Sentencia 17 de junio de 2005. Serie C No 125.

Corte IDH: Caso González y otras ("Campo Algodonero") vs. México. Excepción Preliminar, Fondo, Reparaciones y Costas. Sentencia de 16 de noviembre de 2009. Serie C No 205, para. 243.

Corte Suprema de Chile: Recurso de Protección. Rol No 117-1994. Sentencia de fecha 14 de octubre de 1994.

Corte Suprema de Chile: Humberto Palza Carvacho con Dirección de Riego y Ministerio de Obras Públicas. (Lago Chungará Parque Nacional Lauca). Sentencia de 19 de diciembre de 1995.

Corte Suprema de Chile: Horvath Kiss, Antonio y otros con Comisión Nacional del Medio Ambiente. Recurso de Protección. Rol No 4658-96. Sentencia de fecha 19 de marzo de 1997.

Corte Suprema de Chile: Girardi Lavín y otros con Comisión Regional del Medio Ambiente de Magallanes y Antártica Chilena. Sentencia de fecha 21 de septiembre de 1999. 
Corte Suprema de Chile: Central Termoeléctrica Campiche. Recurso de Protección. Rol No 1219-2009. Sentencia de fecha 22 de junio del 2009.

Corte Suprema de Chile: Empresa Expo Pork Meat Chile S.A. Recurso de Protección. Rol No 5191-2010. Sentencia de fecha 18 de enero de 2011.

Corte Suprema de Chile: Consejo de Defensa del Estado con García Brocal, Julio y otro. Sentencia de reemplazo. Rol No 4033-2013. Sentencia de fecha 3 de octubre de 2013.

Corte Suprema de Chile: Flores Tapia, Cristián y otros con Minera Los Pelambres. Sentencia de reemplazo. Rol No 12938-2013. Sentencia de fecha 21 de octubre de 2014.

E.C.H.R.: Kutic vs. Croatia. Application No 48778/99. Judgment, June 1'st, 2002.

E.C.H.R.: Case of Siliadin v. France (Application No 73316/01) Judgment, July $2^{\text {th }} 2005$, october $26^{\text {th }} 2005$.

Tribunal Constitucional: Rol No 577-06. Sentencia de fecha 26 de abril de 2007.

Tribunal Constitucional: Rol No 1309. Sentencia de fecha 20 de abril de 2010.

Tribunal Constitucional: Rol No 1988-2011. Sentencia de fecha 24 de junio de 2011.

Tribunal Constitucional: Rol No 2386-12. Sentencia de fecha 23 de enero de 2013.

Tribunal Constitucional: Rol No 2299-12. Sentencia de fecha 29 de enero de 2014.

Tribunal Constitucional: Rol No 2299-12. Sentencia de fecha 29 de enero de 2014.

Tribunal Constitucional: Rol No 2643-2014. Sentencia de fecha 27 de enero de 2015.

Tribunal Constitucional: Rol No 2693-14. Sentencia de fecha 13 de octubre de 2015

\section{NORMAS CITADAS}

Comité de Derechos Económicos, Sociales y Culturales (2000): Observación General No 14 . El derecho al disfrute del nivel más alto posible de salud. N.U. Doc. E/C.12/2000/4.

Convención sobre la protección del patrimonio mundial, cultural y natural, Unesco, 1972.

Constitución de la Organización Mundial de la Salud.

Constitución Política del Estado Plurinacional de Bolivia.

Declaración de Alma Ata de 1978. Conferencia Internacional sobre Atención Primaria de Salud: Declaración de Alma Ata, URSS, 6-12 de septiembre de 1978.

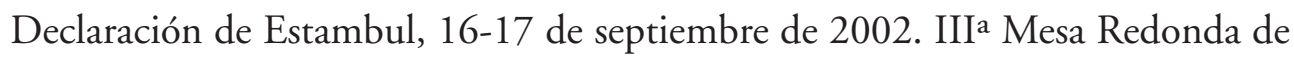
Ministros de Cultura.

Declaración de las Naciones Unidas sobre los derechos de los pueblos indígenas. 
Declaración Universal de la Unesco sobre la Diversidad Cultural, Anexo II, No 14. Protocolo Adicional a la Convención Americana sobre Derechos Humanos en materia de Derechos Económicos, Sociales y Culturales, Protocolo de San Salvador, 1988.

Vers une Constitution Verte de l'UE. Agosto de 2003. Disponible en: http:// www.greenpeace.org/eu-unit/Global/eu-unit/reports-briefings/2007/5/versune-constitution-verte-de.pdf. Visitado: [5/12/2015].

World Health Forum, Vol. 17, No 4, 1996. 